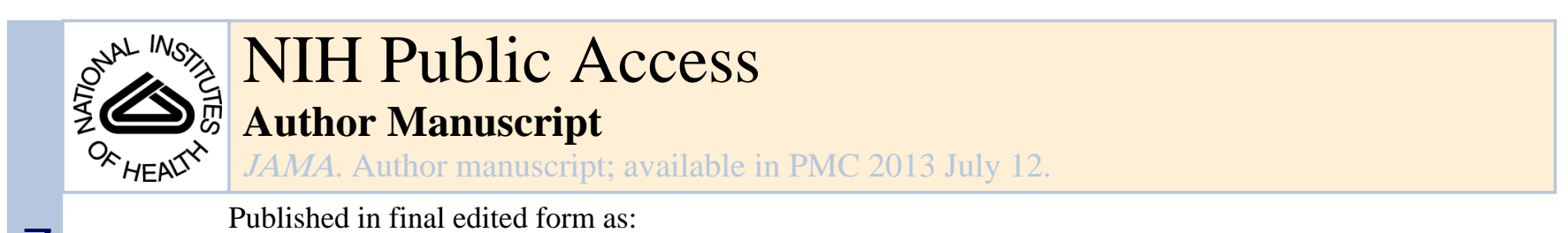

Published in final edited form as:

JAMA. 2012 June 13; 307(22): 2418-2429. doi:10.1001/jama.2012.5521.

\title{
Benefits and Harms of CT Screening for Lung Cancer: A Systematic Review
}

\author{
Peter B. Bach, MD, MAPP, \\ Memorial Sloan-Kettering Cancer Center, New York, NY \\ Joshua N. Mirkin, BA, \\ College of Medicine, SUNY Downstate Medical Center, Brooklyn, NY \\ Thomas K. Oliver, BA, \\ American Society of Clinical Oncology, Alexandria, VA \\ Christopher G. Azzoli, MD, \\ Memorial Sloan-Kettering Cancer Center, New York, NY \\ Don Berry, PhD, \\ M.D. Anderson Cancer Center, Houston, TX
}

Otis W. Brawley, MD,

The American Cancer Society, Atlanta, GA

Tim Byers, MD, MPH,

Colorado School of Public Health, Denver, CO

Graham A. Colditz, MD, DrPH,

Washington University School of Medicine, St. Louis, MO

Michael K. Gould, MD, MS,

Kaiser Permanente Southern California

James R. Jett, MD,

National Jewish Health Center, Denver, CO

Anita L. Sabichi, MD,

Baylor College of Medicine

Rebecca Smith-Bindman, MD,

University of California, San Francisco, CA

Douglas E. Wood, MD,

Contact information: Peter B. Bach, MD, MAPP, 1275 York Avenue, Box 44, New York, NY 10065, 646-888-4474 tel, 646-227-7102 fax, Bachp@mskcc.org.

Conflicts of Interest:

All authors have completed and submitted the ICJME form for Disclosure of Potential Conflicts of Interest. Dr. Azzoli, Dr. Brawley, Dr. Byers, Dr. Colditz, Mr. Mirkin, Mr. Oliver, Dr. Smith-Bindman and Dr. Qaseem have reported no conflicts. Dr. Bach reported that he has received speaking fees from Genentech. Dr. Detterbeck reported that he was reimbursed for travel costs associated with his work on the Oncimmune advisory board, and has participated without compensation in a symposium on CT screening sponsored by Covidien. Dr.Berry reported that he is co-owner of Berry Consultants LLC which designs adaptive clinical trials for pharmaceutical companies, medical device companies and NIH cooperative groups. To the best of his knowledge none of these parties have any interest in lung cancer screening. Dr. Gould reported that he receives grant support from the National Cancer Institute. Dr. Jett reported that he has grants pending for work related to screening and early detection of lung cancer with Oncimmune and Isense. Dr. Sabichi reported her membership on the National Cancer Institute's PDQ Prevention and Screening Editorial Board and her possession of a pending patent for a test for the detection of bladder cancer. Dr. Wood reported his participation in the development of the National Comprehensive Cancer Network's clinical practice guidelines for lung cancer screening in his role as Chair of the NCCN Lung Cancer Screening Panel. 
University of Washington

Amir Qaseem, MD, PhD, MHA, FACP, and

American Board of Internal Medicine

Frank C. Detterbeck, MD

Yale School of Medicine

\section{Abstract}

Context-Lung cancer is the leading cause of cancer death. Most patients are diagnosed with advanced disease, resulting in a very low five-year survival rate. Screening may reduce the risk of death from lung cancer.

Objective-A multi-society collaborative initiative (involving the American Cancer Society, the American College of Chest Physicians, the American Society of Clinical Oncology, and the National Comprehensive Cancer Network) was undertaken to conduct a systematic review of the evidence regarding the benefits and harms of lung cancer screening using low dose computed tomography (LDCT), in order to create the foundation for development of an evidence-based clinical guideline.

Data Sources-MEDLINE (OVID: 1996 to April 2012), EMBASE (OVID: 1996 to April 2012), and the Cochrane Library (April 2012).

Study Selection-Of 591 citations identified and reviewed, eight randomized controlled trials and 13 cohort studies of LDCT screening met criteria for inclusion. Primary outcomes were lung cancer mortality and all-cause mortality, and secondary outcomes included nodule detection, invasive procedures, follow-up tests, and smoking cessation.

Data Extraction-Critical appraisal using pre-defined criteria was conducted on individual studies and the overall body of evidence. Differences in data extracted by reviewers were adjudicated by consensus.

Results-Three randomized studies provided evidence on the impact of LDCT screening on lung cancer mortality, of which the National Lung Screening Trial was the most informative, demonstrating that among 53,454 enrolled, screening resulted in significantly fewer lung cancer deaths (356 vs 443 deaths; lung cancer-specific mortality, 247 vs 309 events per 100,000 personyears for LDCT and control groups, respectively; Relative Risk $[\mathrm{RR}]=0.80,95 \%$ Confidence Interval [CI] 0.73-0.93; Absolute Risk Reduction $[\mathrm{ARR}]=0.33 \%, \mathrm{P}=0.004)$. The other 2 smaller studies showed no such benefit. In terms of potential harms of LDCT screening, across all trials and cohorts, about $20 \%$ of individuals in each round of screening had positive results requiring some degree of follow-up, while approximately $1 \%$ had lung cancer. There was marked heterogeneity in this finding and in the frequency of follow-up investigations, biopsies, and the percent of surgical procedures performed in those with benign lesions. Major complications in those with benign conditions were rare.

Conclusions-LDCT screening may benefit individuals at an elevated risk for lung cancer, but uncertainty exists about potential harms and the generalizability of results.

\section{Background}

Lung cancer is the leading cause of cancer death in the United States (and worldwide), causing as many deaths as the next four most deadly cancers combined (breast, prostate, colon and pancreas). ${ }^{1}$ Despite a slight decline since 1990 in the US, lung cancer will claim $>160,000$ American lives in $2012 .^{2}$ Most patients diagnosed with lung cancer today already have advanced disease (40\% are stage IV, $30 \%$ are stage III), and the current five-year survival rate is only $16 \% .^{3}$ 
Earlier randomized controlled trials (RCT) involving chest radiographs (CXR) and sputum cytology for lung cancer screening found that these strategies detected slightly more lung cancers, smaller and more stage I tumors, but the detection of a larger number of early stage cancers was not accompanied by a reduction in the number of advanced lung cancers or lead to a reduction in lung cancer deaths. ${ }^{4-14}$ Renewed enthusiasm for lung screening arose with the advent of low dose computerized tomography (LDCT) imaging, which is able to identify smaller nodules than can CXR.

This systematic review focuses on the evidence regarding the benefits and harms of LDCT screening for lung cancer. Other potential screening methods (e.g. CXR, sputum cytology or biomarkers, exhaled breath) are not addressed. This review is a collaborative initiative of the American Cancer Society (ACS), the American College of Chest Physicians (ACCP), the American Society of Clinical Oncology (ASCO), and the National Comprehensive Cancer Network (NCCN), and forms the basis for the clinical practice guideline of the ACCP and ASCO (Box xx - link to full guideline in box?). This work will be re-assessed when pertinent new data become available, consistent with the Institute of Medicine's recommendations for guideline development. ${ }^{15}$

\section{Methods}

ACS, ACCP, ASCO and NCCN assembled a panel of experts, representing the relevant clinical disciplines and the consumer's perspective. All members cleared all organizations' conflict of interest policies for participation in guideline development; none received compensation for participation. The sponsoring organizations donated staff time supported by their general administrative funds. No industry funds were used in the support of this endeavor. The panel defined a process for selection, data extraction and outcomes assessment to produce a thorough evaluation of LDCT screening relative to patient-centered outcomes, including quantifying potential benefits and harms. The target patient population for this initiative is individuals at elevated risk of developing lung cancer due to age and smoking history; and the target audience includes physicians, allied professionals and policy makers. The panel was divided into evidence review and writing sub-committees, focusing on the following key questions:

1. What are the potential benefits of screening individuals at elevated risk of developing lung cancer using LDCT?

2. What are the potential harms of screening individuals at elevated risk of developing lung cancer using LDCT?

3. Which groups are most likely to benefit or not benefit from screening?

4. In what setting is screening likely to be effective?

The literature search was developed and conducted by an experienced systematic reviewer using MEDLINE (OVID: 1996 to April 8, 2012), EMBASE (OVID: 1996 to April 8, 2012), and the Cochrane Library (April 20,2012). Additional citations were gleaned from the reference lists of related papers and review articles. The literature search included MeSH and Emtree headings and related text and keyword searches in a manner that combined terms related to lung cancer, population screening and LDCT (eAppendix 1). The search was limited to published data only because it was felt that any unpublished preliminary data identified would add little to inform the primary outcomes of interest.

Studies were eligible for inclusion if they involved either a RCT using LDCT screening for lung cancer in one arm, or a non-comparative cohort study of LDCT screening, provided they reported at least one of the following outcomes: lung-cancer-specific or all-cause mortality, nodule detection rate, frequency of additional imaging, frequency of invasive 
diagnostic procedures (e.g. needle or bronchoscopic biopsy, surgical biopsy, surgical resection) complications from the evaluation of suspected lung cancer, and the rate of smoking cessation or re-initiation. For lung-cancer-specific and all-cause mortality endpoints, only RCT data were considered eligible for inclusion; for other endpoints, data from the LDCT arm of both RCTs and cohort studies were included. Exclusion criteria include studies that only assessed screening among those with risk factors other than smoking (e.g. asbestos), those not published in English, and meta-analysis or case-series reports of outcomes only among patients diagnosed with lung cancer.

The above exclusion criteria were determined a priori and guided whether data identified by the systematic literature review was judged to have been reported in a manner appropriate for inclusion. Articles were selected and data were extracted independently by a minimum of two reviewers. At the point of abstract review, if one of two reviewers indicated that a citation may be relevant, the full text article was retrieved. Upon full text review, if there was a discrepancy among the two reviewers, a third reviewer determined eligibility and the reviewers came to consensus. In addition, the third reviewer also verified that articles deemed ineligible did not actually meet eligibility criteria. Between the three reviewers, discrepancies occurred in approximately $12 \%$ of cases and were resolved through consensus. Most notably, the small RCT by Garg et al and the smoking cessation study by Schnoll et al were originally excluded, but the decision was reversed upon further review. ${ }^{16,17}$ Common reasons for exclusion included the identification of narrative reviews, studies that did not involve high risk smoking populations or studies that only followed patients diagnosed with lung cancer. A full list of the studies excluded from the systematic review and the reasons for exclusion is available from the authors.

The risk of bias was assessed by a minimum of two reviewers using pre-specified criteria (eAppendix 2) and discrepancies were resolved through consensus.

The frequency of nodule detection across studies was analyzed both unadjusted and stratified by multiple study design characteristics (e.g. CT collimation, minimum smoking exposure criteria for study enrollment, stated threshold for labeling a finding "positive" or "suspicious").

\section{Results}

\section{Literature Search Results}

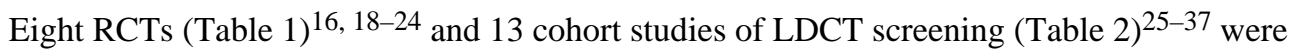
selected from 591 citations identified by the literature search (eAppendix 3). Two RCTs (LSS and DLCST) were pilot studies preceding larger trials (NLST and NELSON, respectively). Several trials are ongoing with only preliminary data currently available. Two RCTs were excluded because they lacked data on key endpoints; one RCT and several cohort studies were excluded because they involved populations at risk due to factors other than smoking or were for general population screening. The cohort study papers of the Early Lung Cancer Action Project (ELCAP) were included, but not the ELCAP case-series or meta-analysis papers. For studies reported in multiple publications, all reports were reviewed but earlier papers superseded by more mature data are not referenced.

A formal assessment of the risk of bias in the RCTs (eTable 1) discloses a low risk in NLST and DLCST, and variable results and an incomplete ability to assess the risk in other studies (often because only preliminary reports of ongoing studies are available). The risk of bias in the cohort studies is variable and often high (usually because justification of sample size, definition of a primary endpoint or funding sources was lacking). 
Across the RCTs, the minimum smoking history required for enrollment ranged from 15-30 pack years (i.e. cigarette packs smoked per day multiplied by years of smoking), with a maximum time since quitting smoking ranging from 10 years to an unlimited number of years (Table 1). The lower age limit ranged from 47 to 60 years, and the upper limit from 69 to 80 years. There was greater variation in entry criteria in the cohort studies (Table 2). Thus, the underlying risk for lung cancer varies substantially. Generally speaking, the NLST, LSS and Garg studies focused on higher risk, DLCST, ITALUNG and DANTE on both higher and intermediate risk and NELSON and Depiscan on a broad range of risk among participants. ${ }^{16,18,20-24,38}$ Although estimating the average risk of all participants in any of these studies is difficult due to lack of granular data, the minimum risk level in each study can be approximated using established formulas. ${ }^{39,40}$ Over 10 years, the risk of being diagnosed with lung cancer for participants meeting minimum entry criteria of each study, assuming they had quit smoking at time of study entry, are approximately $2 \%$ for NLST, $1 \%$ for DLSCT and considerably less than $1 \%$ for NELSON. The nodule size deemed large enough to investigate further ranged from "any size" to $>5 \mathrm{~mm}$; the size that triggered an invasive intervention (when specified) ranged from 6-15 $\mathrm{mm}$ (Tables 1,2).

\section{What are the Potential Benefits of Screening Individuals at Elevated Risk of Developing Lung Cancer Using LDCT?}

Effect on Mortality-Three RCTs have reported the impact of LDCT screening on lungcancer-specific mortality (Table 3). The NLST found that three annual rounds of screening (baseline, and 1and 2 years later) with LDCT resulted in a $20 \%$ relative decrease in deaths from lung cancer relative to CXR over a median of 6.5 years of follow-up $(\mathrm{p}=0.004) .{ }^{22} \mathrm{In}$ absolute terms, the chance of dying from lung cancer was $0.33 \%$ less over the study period in the LDCT group (87 avoided deaths over 26,722 screened participants), meaning 310 people must participate in screening to prevent one lung cancer death. Based on a slightly different denominator the NLST authors reported the number-needed-to-screen with LDCT was 320 to prevent one lung cancer death, and based on the confidence intervals overall the confidence interval on the number needed to screen ranges from $\mathrm{xx}$ to $\mathrm{yy}$. The considerably smaller ongoing DANTE and DLST studies each compare 5 annual rounds of LDCT screening to usual care; after a median of 34 and 58 months of follow-up, no statistically significant difference in lung cancer mortality was observed in either study (Dante: RR = $0.97,95 \%$ CI $0.71-1.32, \mathrm{p}=0.84)$; (DLST: RR $=1.15,95 \%$ CI $0.83-1.61, \mathrm{p}=0.43) .{ }^{21}$

All three studies reported on the risk of death from any cause (Table 3) between study arms, and directly or indirectly on the risk of death from any cause other than lung cancer. Only the NLST found a difference in this endpoint, with fewer deaths overall in the LDCT vs. the CXR arm (1,303 vs. 1,395 deaths per 100,000 person-years, respectively). Analyses focusing exclusively on deaths not due to lung cancer found no significant differences in any of the three studies. ${ }^{22}$

Effect on Smoking Behavior-No studies have evaluated whether public statements regarding LDCT screening's benefits affect smoking behavior. Speculation exists that undergoing LDCT screening may result in justification of continued smoking, or may represent an opportunity for successful smoking cessation. Studies examining the smoking behavior of LDCT screened individuals have not found evidence that cessation or reinitiation rates are meaningfully altered by participation in screening (eTable 2 ). ${ }^{41-43}$

\section{What are the Potential Harms of Screening Individuals at Elevated Risk of Developing Lung Cancer Using LDCT?}

Detection of Abnormalities-LDCT identifies both cancerous and benign non-calcified nodules - the latter are often called "false positives". Although most LDCT screening studies 
have reported on nodules detected, the categorization and manner of reporting is inconsistent (e.g. it is sometimes unclear if newly identified nodules are assigned to that round, or to an earlier round if they can be retrospectively seen on an earlier LDCT). Likewise, size thresholds that would trigger an invasive work-up are variously and inconsistently reported as are the potential denominators such as per-screening round, or per-person year.

Across studies, the average nodule detection rate per round of screening was $20 \%$ (Table 5, eFigure 1), but varied from 3-30\% in RCTs and 5-51\% in cohort studies. Most studies reported that $>90 \%$ of nodules were benign. In general there is a tendency towards lower nodule detection rates in repeat screening rounds, but the data and reporting is inconsistent (Table 5, e Figure 2). In the NLST the rate of detection did not decrease until the third round. In that round the study protocol allowed for ignoring nodules that had been present in the prior rounds. We were unable to find any relation between study features, such as smoking history of study enrollees, CT scan settings, nodule size cutoffs, and reported nodule detection rates.

Most often a detected nodule triggered further imaging, but the underlying management protocols were inconsistently reported in the studies. Whether all additional imaging tests were captured in the studies was also uncertain: reported follow-up imaging rates may be underestimated. The frequency of further CT imaging among screened individuals ranged from $1 \%$ in Veronesi to $44.6 \%$ in Sobue. The frequency of further PET imaging among screened individuals, exhibited much less variation, ranging from $2.5 \%$ in Bastarrika to $5.5 \%$ in the NLST.". $22,25,28,32$ The frequency of invasive evaluation of detected nodules was generally low but varied considerably (Table 6, eFigure 3 ). No patterns were apparent that explained this heterogeneity. In the NLST $1.2 \%$ of patients who were not found to have lung cancer underwent an invasive procedure such as needle biopsy or bronchoscopy, while $0.7 \%$ of patients who were not found to have lung cancer had a thorocoscopy, mediastinoscopy or thoracotomy. ${ }^{22}$ In the NELSON study these numbers were $1.2 \%$ and $0.6 \%$ respectively. ${ }^{18}$ Invasive non-surgical procedures in patients with benign lesions were common (e.g. $73 \%$ in NLST).

Complications of Diagnostic Procedures Stemming from Screening-The only study reporting on complications resulting from LDCT screening is the NLST. Overall, the frequency of death occurring within 2 months of a diagnostic evaluation of a detected finding was 8 per 10,000 individuals screened by LDCT, and 5 per 10,000 individuals screened by CXR. Some of the deaths after a diagnostic evaluation were presumably unrelated to follow-up procedures, as 1.9 and 1.5 per 10,000 occurred within 2 months when the diagnostic evaluation involved only an imaging study. Deaths most clearly related to follow-up procedures were those occurring within 2 months when the most recent procedure was a bronchoscopy or needle biopsy (3.4 per 10,000 screened by LDCT and 2.2 per 10,000 screened by CXR). Approximately one third of the deaths occurred within 2 months of a surgical procedure in both arms, and the vast majority of these were in the patients with cancer, suggesting perhaps that the surgical procedures in those with cancer were more extensive (i.e. resection rather than biopsy; such details were not reported). The 60-day perioperative mortality for patients with lung cancer who underwent a surgical procedure was $1 \%$ for the LDCT arm and .2\% for the CXR arm.

Overall, the frequency of a major complication occurring during a diagnostic evaluation of a detected finding was 33 per 10,000 individuals screened by LDCT, and 10 per 10,000 individuals screened by CXR. The rate of (presumably unrelated) complications following imaging alone was similar and low (1.1 and 1.5 per 10,000 screened); the complication rate after a bronchoscopy or needle biopsy was also low (1.5 and 0.7 per 10,000 for LDCT and CXR, respectively). The vast majority of major complications occurred after surgical 
procedures, and in those patients with lung cancer. The rate of major complications in those patients with lung cancer who underwent surgery was $14 \%$.

Focusing only on those patients who had nodules detected by LDCT that turned out to be benign, death occurred within 60 days among $0.06 \%$, and major complications occurred among $0.36 \%$. About half of the deaths occurred after imaging alone, whereas the majority of major complications occurred after a surgical procedure (details unknown). Calculating these numbers for an entire screened population, the risk of death or major complications following diagnostic events (including imaging) for what turns out to be a benign nodule is 4.1 and 4.5 per 10,000. This is higher than in the CXR arm (1.1 and 1.5 per 10,000).

Overdiagnosis-Overdiagnosis refers to histologically confirmed lung cancers identified through screening that would not impact the patient's lifetime if left untreated. This includes patients who are destined to die of another cause (e.g. a co-morbidity or an unexpected event).$^{44}$ Earlier studies suggested that CXR screening may have an overdiagnosis rate of roughly $25 \% .45,46$ The overdiagnosis rate for LDCT screening cannot yet be estimated; NLST data shows a persistent gap of about 120 excess lung cancers in the LDCT vs. the CXR arm, but further follow-up is needed.

Radiation Exposure-The effective dose of radiation of LDCT is estimated to be 1.5 $\mathrm{mSv}$ per examination, but there is substantial variation in actual clinical practice. However, diagnostic chest CT $(\sim 8 \mathrm{mSv})^{47}$ or PET-CT $(\sim 14 \mathrm{mSv})^{47-49}$ to further investigate detected lesions rapidly increases the exposure and accounts for most of the radiation exposure in screening studies. We estimate that NLST participants received $\sim 8 \mathrm{mSv}$ per participant over the three years, including both screening and diagnostic examinations (averaged over the entire screened population). Estimates of harms from such radiation come from several official bodies and commissioned studies, ${ }^{50,51}$ based on dose extrapolations from atomic bombings and also many studies of medical imaging. ${ }^{52,53}$ Using the NLST data these models predict approximately one cancer death caused by radiation from imaging per 2500 subjects screened. Therefore, the benefit in preventing lung cancer deaths in NLST is considerably greater than the radiation risk - which furthermore only becomes manifest 10 20 years later. However, for younger individuals or those with lower risk of developing lung cancer the tradeoff would be less favorable. Preliminary modeling studies suggest that potential risks may vastly outweigh benefits in non-smokers or those sage $42 .{ }^{54}$ Further study, including the effects of ongoing annual LDCT beyond three successive years, is needed.

Impact on Quality of Life-The impact of LDCT screening on quality of life (QOL) is unclear. We found only one study, in which $88-99 \%$ of 351 subjects reported no discomfort, but $46 \%$ reported psychological distress while awaiting results. ${ }^{55}$ One can speculate about QOL benefits due to lower morbidity from advanced lung cancer, but there are also potential detriments due to anxiety, costs, and harms from the evaluation of both false positive scans and overdiagnosed cancers.

\section{Which Patients are Likely to Benefit or not Benefit from LDCT Screening?}

The NLST population is the only one for whom a lung cancer mortality benefit from LDCT has been demonstrated (age 55-74, 230 pack-years of smoking, and quit $₫ 5$ years prior to entry). Other studies are too small, too preliminary, or too poorly designed to support meaningful conclusions. The value of LDCT screening is likely determined primarily by the risk of lung cancer versus competing causes of death. Little information exists regarding comorbidities, but presumably the NLST participants were deemed healthy. We estimate an average risk of developing lung cancer within 10 years of $\sim 10 \%$ for the NLST population in 
the absence of screening (estimated median age 62 and $~ 50$ pack-years of smoking).

However, the risk for individual NLST participants most likely varied by more than 10 -fold over that time period, from $<2 \%$ to $>20 \%$, and it is unclear which groups experienced benefit. ${ }^{39,40}$ Further research and modeling studies are needed to provide an evidence base for refining the selection criteria for screening. Other risk factors for lung cancer are well known (e.g. family history of lung cancer, occupational exposures, personal history of lung or certain other cancers), but how these might affect selection for LDCT screening has not been studied.

\section{In What Setting Is Screening Likely to Be Effective?}

A summary (eTable 3 ) of the setting of the NLST (the only positive study) demonstrates that most $(76 \%)$ of the NLST sites were National Cancer Institute designated cancer centers, and $82 \%$ were large academic medical centers with $>400$ hospital beds. We believe that all have specialized thoracic radiologists and board certified thoracic surgeons on staff. The CT scanners used in the NLST underwent ongoing extensive quality control, and the scans were interpreted by chest radiologists who underwent specific training and quality control in the interpretation of images and wording of screening LDCT findings. ${ }^{48}$ A nodule management algorithm was included in the NLST but adherence or the setting in which nodules were managed was not mandated or tracked by the study. ${ }^{48}$

Most other RCTs and cohort studies of LDCT screening were conducted in facilities similar to the NLST sites: academic medical centers, large hospitals, with the involvement of relevant subspecialist services and a defined nodule management algorithm. The impact of details of the setting of LDCT screening has not been tested, but the variability in rates of false positive LDCT scans, further imaging and procedures suggests these may be important.

\section{Discussion}

This paper summarizes the systematic review conducted by a multi-society collaborative effort examining the risks and benefits of LDCT screening for lung cancer, and forms the basis of the American College of Chest Physicians and the American Society of Clinical Oncology clinical practice guideline (Box, link to full practice guideline). The guideline is based on the finding that a reasonable amount of data has been reported regarding the outcomes for LDCT screening for lung cancer and that some conclusions can be drawn regarding its risks and benefits despite many areas of uncertainty.

A recent large, high quality RCT (the NLST) found that annual LDCT screening reduced the relative risk of death from lung cancer by $20 \%$, and the absolute risk by $0.33 \%$ in a population with a substantially elevated risk for lung cancer. Two smaller RCT's (DANTE and DLSCT) comparing LDCT to usual care found no benefit of LDCT screening, but are best interpreted as neither confirming nor contradicting the NLST findings. Because studies a recent large $(\mathrm{N}=154,901) \mathrm{RCT}$ demonstrated no lung cancer mortality difference between CXR screening and usual care, the interventions in these three studies are reasonably comparable. ${ }^{56}$

The literature supports the conclusion that LDCT screening can lead to harm. It identifies a relatively high percentage of subjects with nodules (average 20\%), the vast majority of which are benign. The additional imaging that these nodules trigger increases radiation exposure. The rates of surgical biopsy are also variable $(<1-4 \%)$ as are the percentage of surgical procedures performed for benign disease. The rate of major, and sometimes fatal, complications among those with benign conditions is low. 
The unexplained heterogeneous rates of nodule detection, additional imaging and invasive procedures that occurred within the structured settings of the controlled trials of LDCT raise concerns about how easily LDCT can be more broadly implemented. There is already substantial variability in the US in the rates and complications of pulmonary needle biopsy 57 and outcomes of lung cancer surgery, being considerably better in dedicated centers (such as those conducting LDCT trials). ${ }^{58,59}$ Furthermore, compliance with screening is consistently lower in cohort studies than in the NLST, and could be worse with unstructured implementation, with resulting diminished benefits. Analogous concerns in breast cancer screening led to the Mammography Quality Standards Act. The position statement by the International Association for the Study of Lung Cancer recommends demonstration projects to evaluate implementation of LDCT screening, establishment of quality metrics, and multiple task forces to address the many critical areas of uncertainty. ${ }^{60}$ Given all of these issues, performing a LDCT scan outside of a structured organized process appears to be beyond the current evidence base for LDCT lung cancer screening.

The fear associated with even a slight suspicion of lung cancer highlights the need for careful education of LDCT participants, and the need for carefully worded scan interpretations. Furthermore, even a small negative impact on smoking behavior (either lower quit rates or higher recidivism) could easily offset the potential gains from LDCT screening in a population. ${ }^{61}$ Smoking cessation should be considered a valuable component of any screening program. Finally, in the setting of rising healthcare costs, the relative costeffectiveness of LDCT screening compared to other interventions will be a topic of discussion and concern in policy spheres. Medicare is allowed to contemplate a preventive services cost-effectiveness before adding it to the package of preventive benefits (Medicare Improvements for Patients and Providers Act of 2008). Now that an estimate is available of effectiveness, an estimate of cost-effectiveness could be generated, but none based on study data have yet been published. Some elements of such an analysis that will be critical will be determining what the price of the component services will be, how frequently follow-up procedures will be required, and how much underlying risk of disease affects costeffectiveness. It is likely that the test will be much less cost-effective when applied to individuals at lower risk of lung cancer, because more individuals will need to be scanned to prevent each death from the disease. Making screening available in settings without an organized approach to the evaluation and management of LDCT findings may also lower cost-effectiveness, if the frequency of interventions and procedures is higher in these settings. $61-64$

Other questions regarding the generalizability of available findings also remain, such as the extent to which reported findings will generalize from the clinical studies to the broader community, and the extent to which one can extrapolate from studies with only a few rounds of screening to an approach that could cover many years of screening. It is possible to speculate that benefits of screening could be enhanced if screening were continued for longer periods, but the risks could be amplified as well. Careful studies are also needed to explore how LDCT screening might affect individuals who are unlike those already studied or who are screened in settings unlike those where previous studies have been conducted.

\section{Supplementary Material}

Refer to Web version on PubMed Central for supplementary material.

\section{Acknowledgments}

We are grateful for the assistance of Sandra Zelman Lewis, PhD (ACCP), Mark Somerfield, PhD (ASCO), Jerry Seidenfeld, PhD (ASCO), Joan McClure, MS (NCCN) and Kate O'Toole, MBA (ACS), who provided administrative assistance, Nancy Keating, MD, MPH (ASCO), Carolyn Dressler, MD, MPA (ASCO), and Maryann 
Napoli (the Center for Medical Consumers) who provided editorial assistance, and Geoffrey Schnorr, BS (MSKCC) who provided administrative, editorial and research assistance. The Panel also wishes to express its gratitude to Dr. Nancy Lynn Keating and Dr. Carolyn Dressler and members of the American Society of Clinical Oncology Clinical Practice Guideline Committee for their thoughtful reviews of earlier drafts. Each of these individuals are employed by their respective organizations but did not receive any compensation specific to this project.

Members of the panel played the following roles: Peter B. Bach (project lead), Joshua Mirkin (project coordinator), Evidence Sub-Committee: Don Berry, Graham Colditz, Michael K. Gould (Chair), Rebecca Smith-Bindman; Writing Sub-Committee: Christopher G. Azzoli, Otis W. Brawley, Timothy Byers (co-Chair), James Jett, Maryann Napoli, Anita Sabichi, Douglas E. Wood, Amir Qaseem, Frank Detterbeck (co-chair)

Peter B. Bach had full access to all the data in the study and takes responsibility for the integrity of the data and the accuracy of the data analysis.

The American College of Chest Physicians, American Cancer Society, American Society of Clinical Oncology and the National Comprehensive Cancer Network all reviewed and approved the manuscript, but did not have a role in the design and conduct of the study; the collection, management, analysis and interpretation of the data; or in the preparation of the manuscript.

Funding:

There was no external funding for this project.

\section{References}

1. Jemal A, Siegel R, Xu J, Ward E. Cancer statistics, 2010. CA Cancer Journal for Clinicians. 2010; 60(5):277-300.

2. American Cancer Society. Cancer Facts \& Figures 2012. Atlanta: American Cancer Society; 2012.

3. Howlander, N.; Noone, AM.; Krapcho, M.; Neyman, N.; Aminou, R.; Waldron, W.; Altekruse, SF.; Kosary, CL.; Ruhl, J.; Tatalovich, Z.; Cho, H.; Mariotto, A.; Eisner, MP.; Lewis, DR.; Chen, HS.; Feuer, EJ.; Cronin, KA.; Edwards, BK., editors. SEER Cancer Statistics Review. Bethesda, MD: National Cancer Institute; 1975-2008.

4. Tockman MS. Survival and Mortality from Lung Cancer in a Screened Population. Chest. 1986 Apr 1; 89(4 Supplement):324S-325S. 1986. [PubMed: 3956302]

5. Tockman MS, Mulshine JL. Sputum screening by quantitative microscopy: a new dawn for detection of lung cancer? Mayo Clin Proc. 1997 Aug; 72(8):788-790. [PubMed: 9276609]

6. Prorok PC, Andriole GL, Bresalier RS, et al. Design of the Prostate, Lung, Colorectal and Ovarian (PLCO) Cancer Screening Trial. Control Clin Trials. 2000 Dec; 21(6 Suppl):273S-309S. [PubMed: 11189684]

7. Payne PW, Sebo TJ, Doudkine A, et al. Sputum screening by quantitative microscopy: a reexamination of a portion of the National Cancer Institute Cooperative Early Lung Cancer Study. Mayo Clin Proc. 1997 Aug; 72(8):697-704. [PubMed: 9276595]

8. Palmisano WA, Divine KK, Saccomanno G, et al. Predicting lung cancer by detecting aberrant promoter methylation in sputum. Cancer Res. 2000 Nov 1; 60(21):5954-5958. [PubMed: 11085511]

9. Miozzo M, Sozzi G, Musso K, et al. Microsatellite alterations in bronchial and sputum specimens of lung cancer patients. Cancer Res. 1996 May 15; 56(10):2285-2288. [PubMed: 8625300]

10. Melamed MR. Lung cancer screening results in the National Cancer Institute New York study. Cancer. 2000 Dec 1; 89(11 Suppl):2356-2362. [PubMed: 11147612]

11. Mao L, Hruban RH, Boyle JO, Tockman M, Sidransky D. Detection of oncogene mutations in sputum precedes diagnosis of lung cancer. Cancer Res. 1994 Apr 1; 54(7):1634-1637. [PubMed: 8137272]

12. Kubik A, Polak J. Lung cancer detection. Results of a randomized prospective study in Czechoslovakia. Cancer. 1986 Jun 15; 57(12):2427-2437. [PubMed: 3697941]

13. Fontana RS, Sanderson DR, Woolner LB, Taylor WF, Miller WE, Muhm JR. Lung cancer screening: the Mayo program. J Occup Med. 1986 Aug; 28(8):746-750. [PubMed: 3528436]

14. Brett GZ. The value of lung cancer detection by six-monthly chest radiographs. Thorax. 1968 Jul; 23(4):414-420. [PubMed: 5664703] 
15. Institute of Medicine. Finding What Works in Health Care: Standards for Systematic Reviews. Washington, DC: National Academy of Sciences; 2011.

16. Garg K, Keith RL, Byers T, et al. Randomized controlled trial with low-dose spiral CT for lung cancer screening: feasibility study and preliminary results. Radiology. 2002 Nov; 225(2):506-510. [PubMed: 12409588]

17. Schnoll RA, Miller SM, Unger M, McAleer C, Halbherr T, Bradley P. Characteristics of female smokers attending a lung cancer screening program: a pilot study with implications for program development. Lung Cancer. 2002 Sep; 37(3):257-265. [PubMed: 12234693]

18. van Klaveren RJ, Oudkerk M, Prokop M, et al. Management of lung nodules detected by volume CT scanning. N Engl J Med. 2009 Dec 3; 361(23):2221-2229. [PubMed: 19955524]

19. Saghir Z, Dirksen A, Ashraf H, et al. CT screening for lung cancer brings forward early disease. The randomised Danish Lung Cancer Screening Trial: status after five annual screening rounds with low-dose CT. Thorax. 2012 Apr; 67(4):296-301. [PubMed: 22286927]

20. Lopes Pegna A, Picozzi G, Mascalchi M, et al. Design, recruitment and baseline results of the ITALUNG trial for lung cancer screening with low-dose CT. Lung Cancer. 2009 Apr; 64(1):3440. [PubMed: 18723240]

21. Infante M, Cavuto S, Lutman FR, et al. A randomized study of lung cancer screening with spiral computed tomography: three-year results from the DANTE trial. Am J Respir Crit Care Med. 2009 Sep 1; 180(5):445-453. [PubMed: 19520905]

22. Aberle DR, Adams AM, Berg CD, et al. Reduced lung-cancer mortality with low-dose computed tomographic screening. N Engl J Med. 2011 Aug 4; 365(5):395-409. [PubMed: 21714641]

23. Gohagan JK, Marcus PM, Fagerstrom RM, et al. Final results of the Lung Screening Study, a randomized feasibility study of spiral CT versus chest X-ray screening for lung cancer. Lung Cancer. 2005 Jan; 47(1):9-15. [PubMed: 15603850]

24. Blanchon T, Brechot JM, Grenier PA, et al. Baseline results of the Depiscan study: a French randomized pilot trial of lung cancer screening comparing low dose CT scan (LDCT) and chest Xray (CXR). Lung Cancer. 2007 Oct; 58(1):50-58. [PubMed: 17624475]

25. Veronesi G, Bellomi M, Mulshine JL, et al. Lung cancer screening with low-dose computed tomography: a non-invasive diagnostic protocol for baseline lung nodules. Lung Cancer. 2008 Sep; 61(3):340-349. [PubMed: 18308420]

26. Wilson DO, Weissfeld JL, Fuhrman CR, et al. The Pittsburgh Lung Screening Study (PLuSS): outcomes within 3 years of a first computed tomography scan. Am J Respir Crit Care Med. 2008 Nov 1; 178(9):956-961. [PubMed: 18635890]

27. Menezes RJ, Roberts HC, Paul NS, et al. Lung cancer screening using low-dose computed tomography in at-risk individuals: the Toronto experience. Lung Cancer. 2010 Feb; 67(2):177183. [PubMed: 19427055]

28. Sobue T, Moriyama N, Kaneko M, et al. Screening for lung cancer with low-dose helical computed tomography: anti-lung cancer association project. J Clin Oncol. 2002 Feb 15; 20(4):911-920. [PubMed: 11844811]

29. Swensen SJ, Jett JR, Hartman TE, et al. CT screening for lung cancer: five-year prospective experience. Radiology. 2005 Apr; 235(1):259-265. [PubMed: 15695622]

30. Pastorino U, Bellomi M, Landoni C, et al. Early lung-cancer detection with spiral CT and positron emission tomography in heavy smokers: 2-year results. Lancet. 2003 Aug 23; 362(9384):593-597. [PubMed: 12944057]

31. Henschke CI, Naidich DP, Yankelevitz DF, et al. Early lung cancer action project: initial findings on repeat screenings. Cancer. 2001 Jul 1; 92(1):153-159. [PubMed: 11443621]

32. Bastarrika G, Garcia-Velloso MJ, Lozano MD, et al. Early lung cancer detection using spiral computed tomography and positron emission tomography. Am J Respir Crit Care Med. 2005 Jun 15; 171(12):1378-1383. [PubMed: 15790860]

33. Diederich S, Thomas M, Semik M, et al. Screening for early lung cancer with low-dose spiral computed tomography: results of annual follow-up examinations in asymptomatic smokers. Eur Radiol. 2004 Apr; 14(4):691-702. [PubMed: 14727146] 
34. Novello S, Fava C, Borasio P, et al. Three-year findings of an early lung cancer detection feasibility study with low-dose spiral computed tomography in heavy smokers. Ann Oncol. 2005 Oct; 16(10):1662-1666. [PubMed: 16006584]

35. Callol L, Roig F, Cuevas A, et al. Low-dose CT: a useful and accessible tool for the early diagnosis of lung cancer in selected populations. Lung Cancer. 2007 May; 56(2):217-221. [PubMed: 17316889]

36. MacRedmond R, McVey G, Lee M, et al. Screening for lung cancer using low dose CT scanning: results of 2 year follow up. Thorax. 2006 Jan; 61(1):54-56. [PubMed: 16396954]

37. Picozzi G, Paci E, Lopez Pegna A, et al. Screening of lung cancer with low dose spiral CT: results of a three year pilot study and design of the randomised controlled trial "Italung-CT". Radiol Med. 2005 Jan-Feb;109(1-2):17-26. [PubMed: 15729183]

38. Pedersen JH, Ashraf H, Dirksen A, et al. The Danish randomized lung cancer CT screening trial-overall design and results of the prevalence round. J Thorac Oncol. 2009 May; 4(5):608-614. [PubMed: 19357536]

39. Bach PB, Kattan MW, Thornquist MD, et al. Variations in lung cancer risk among smokers. J Natl Cancer Inst. 2003 Mar 19; 95(6):470-478. [PubMed: 12644540]

40. Lung Cancer Risk Assessment Tools. [Accessed 9/6/2011] 5/30/2003; http://www.mskcc.org/ $\mathrm{mskcc} / \mathrm{html} / 12463 . \mathrm{cfm}$

41. Ashraf H, Tonnesen P, Holst Pedersen J, Dirksen A, Thorsen H, Dossing M. Effect of CT screening on smoking habits at 1-year follow-up in the Danish Lung Cancer Screening Trial (DLCST). Thorax. 2009 May; 64(5):388-392. [PubMed: 19052048]

42. van der Aalst CM, van den Bergh KA, Willemsen MC, de Koning HJ, van Klaveren RJ. Lung cancer screening and smoking abstinence: 2 year follow-up data from the Dutch-Belgian randomised controlled lung cancer screening trial. Thorax. $2010 \mathrm{Jul}$; 65(7):600-605. [PubMed: 20627916]

43. Clark MM, Cox LS, Jett JR, et al. Effectiveness of smoking cessation self-help materials in a lung cancer screening population. Lung Cancer. 2004 Apr; 44(1):13-21. [PubMed: 15013579]

44. Bach PB. Overdiagnosis in lung cancer: different perspectives, definitions, implications. Thorax. 2008 Apr; 63(4):298-300. [PubMed: 18364441]

45. Kubik AK, Parkin DM, Zatloukal P. Czech Study on Lung Cancer Screening: post-trial follow-up of lung cancer deaths up to year 15 since enrollment. Cancer. 2000 Dec 1; 89(11 Suppl):23632368. [PubMed: 11147613]

46. Marcus PM, Bergstralh EJ, Fagerstrom RM, et al. Lung cancer mortality in the Mayo Lung Project: impact of extended follow-up. J Natl Cancer Inst. 2000 Aug 16; 92(16):1308-1316. [PubMed: 10944552]

47. Mettler FA Jr. Huda W, Yoshizumi TT, Mahesh M. Effective doses in radiology and diagnostic nuclear medicine: a catalog. Radiology. 2008 Jul; 248(1):254-263. [PubMed: 18566177]

48. Aberle DR, Berg CD, Black WC, et al. The National Lung Screening Trial: overview and study design. Radiology. 2011 Jan; 258(1):243-253. [PubMed: 21045183]

49. Smith-Bindman R, Lipson J, Marcus R, et al. Radiation dose associated with common computed tomography examinations and the associated lifetime attributable risk of cancer. Arch Intern Med. 2009 Dec 14; 169(22):2078-2086. [PubMed: 20008690]

50. Charles M. UNSCEAR report 2000: sources and effects of ionizing radiation. United Nations Scientific Comittee on the Effects of Atomic Radiation. J Radiol Prot. 2001 Mar; 21(1):83-86. [PubMed: 11281539]

51. ICRP. Radiological protection and safety in medicine, ICRP Publication 73. Annals of the ICRP. 1996; 26(No. 2)

52. Einstein AJ, Henzlova MJ, Rajagopalan S. Estimating risk of cancer associated with radiation exposure from 64-slice computed tomography coronary angiography. JAMA. 2007 Jul 18; 298(3): 317-323. [PubMed: 17635892]

53. Preston DL, Ron E, Tokuoka S, et al. Solid cancer incidence in atomic bomb survivors: 19581998. Radiat Res. 2007 Jul; 168(1):1-64. [PubMed: 17722996] 
54. De González AB, Kwang PK, Berg CD. Low-dose lung computed tomography screening before age 55: Estimates of the mortality reduction required to outweigh the radiation-induced cancer risk. Journal of Medical Screening. 2008; 15(3):153-158. [PubMed: 18927099]

55. van den Bergh KA, Essink-Bot ML, Bunge EM, et al. Impact of computed tomography screening for lung cancer on participants in a randomized controlled trial (NELSON trial). Cancer. $2008 \mathrm{Jul}$ 15; 113(2):396-404. [PubMed: 18484588]

56. Oken MM, Hocking WG, Kvale PA, et al. Screening by chest radiograph and lung cancer mortality: the Prostate, Lung, Colorectal, and Ovarian (PLCO) randomized trial. JAMA. 2011 Nov 2; 306(17):1865-1873. [PubMed: 22031728]

57. Wiener RS, Schwartz LM, Woloshin S, Welch HG. Population-based risk for complications after transthoracic needle lung biopsy of a pulmonary nodule: an analysis of discharge records. Ann Intern Med. 2011 Aug 2; 155(3):137-144. [PubMed: 21810706]

58. Bach PB, Cramer LD, Schrag D, Downey RJ, Gelfand SE, Begg CB. The influence of hospital volume on survival after resection for lung cancer. N Engl J Med. 2001 Jul 19; 345(3):181-188. [PubMed: 11463014]

59. Birkmeyer JD, Siewers AE, Finlayson EV, et al. Hospital volume and surgical mortality in the United States. N Engl J Med. 2002 Apr 11; 346(15):1128-1137. [PubMed: 11948273]

60. Field JK, Smith RA, Aberle DR, et al. International Association for the Study of Lung Cancer Computed Tomography Screening Workshop 2011 report. J Thorac Oncol. 2012 Jan; 7(1):10-19. [PubMed: 22173661]

61. McMahon PM, Kong CY, Bouzan C, et al. Cost-effectiveness of computed tomography screening for lung cancer in the United States. J Thorac Oncol. 2011 Nov; 6(11):1841-1848. [PubMed: 21892105]

62. Black C, Bagust A, Boland A, et al. The clinical effectiveness and cost-effectiveness of computed tomography screening for lung cancer: systematic reviews. Health Technol Assess. 2006 Jan; 10(3):1-90. iii-iv, ix-x.

63. Castleberry AW, Smith D, Anderson C, Rotter AJ, Grannis FW Jr. Cost of a 5-year lung cancer survivor: symptomatic tumour identification vs proactive computed tomography screening. $\mathrm{Br} \mathrm{J}$ Cancer. 2009 Sep 15; 101(6):882-896. [PubMed: 19690541]

64. Reich JM. Cost-effectiveness of computed tomography lung cancer screening. Br J Cancer. 2009 Sep 15; 101(6):879-880. [PubMed: 19738616]

65. Aberle DR, Adams AM, Berg CD, et al. Baseline characteristics of participants in the randomized national lung screening trial. J Natl Cancer Inst. 2010 Dec 1; 102(23):1771-1779. [PubMed: 21119104]

66. Gohagan J, Marcus P, Fagerstrom R, Pinsky P, Kramer B, Prorok P. Baseline findings of a randomized feasibility trial of lung cancer screening with spiral CT scan vs chest radiograph: the Lung Screening Study of the National Cancer Institute. Chest. 2004 Jul; 126(1):114-121. [PubMed: 15249451]

67. Veronesi G, Bellomi M, Scanagatta P, et al. Difficulties encountered managing nodules detected during a computed tomography lung cancer screening program. J Thorac Cardiovasc Surg. 2008 Sep; 136(3):611-617. [PubMed: 18805261]

68. Swensen SJ, Jett JR, Hartman TE, et al. Lung cancer screening with CT: Mayo Clinic experience. Radiology. 2003 Mar; 226(3):756-761. [PubMed: 12601181]

69. Swensen SJ, Jett JR, Sloan JA, et al. Screening for lung cancer with low-dose spiral computed tomography. Am J Respir Crit Care Med. 2002 Feb 15; 165(4):508-513. [PubMed: 11850344]

70. Henschke CI, Yankelevitz DF, Libby DM, et al. Early lung cancer action project: annual screening using single-slice helical CT. Ann N Y Acad Sci. 2001 Dec.952:124-134. [PubMed: 11795431]

71. Diederich S, Wormanns D, Lenzen H, Semik M, Thomas M, Peters PE. Screening for asymptomatic early bronchogenic carcinoma with low dose CT of the chest. Cancer. 2000 Dec 1; 89(11 Suppl):2483-2484. [PubMed: 11147631]

72. Diederich S, Wormanns D, Semik M, et al. Screening for early lung cancer with low-dose spiral CT: prevalence in 817 asymptomatic smokers. Radiology. 2002 Mar; 222(3):773-781. [PubMed: 11867800] 
73. MacRedmond R, Logan PM, Lee M, Kenny D, Foley C, Costello RW. Screening for lung cancer using low dose CT scanning. Thorax. 2004 Mar; 59(3):237-241. [PubMed: 14985561]

74. Infante M, Chiesa G, Solomon D, et al. Surgical procedures in the DANTE trial, a randomized study of lung cancer early detection with spiral computed tomography: comparative analysis in the screening and control arm. J Thorac Oncol. 2011 Feb; 6(2):327-335. [PubMed: 21178639] 


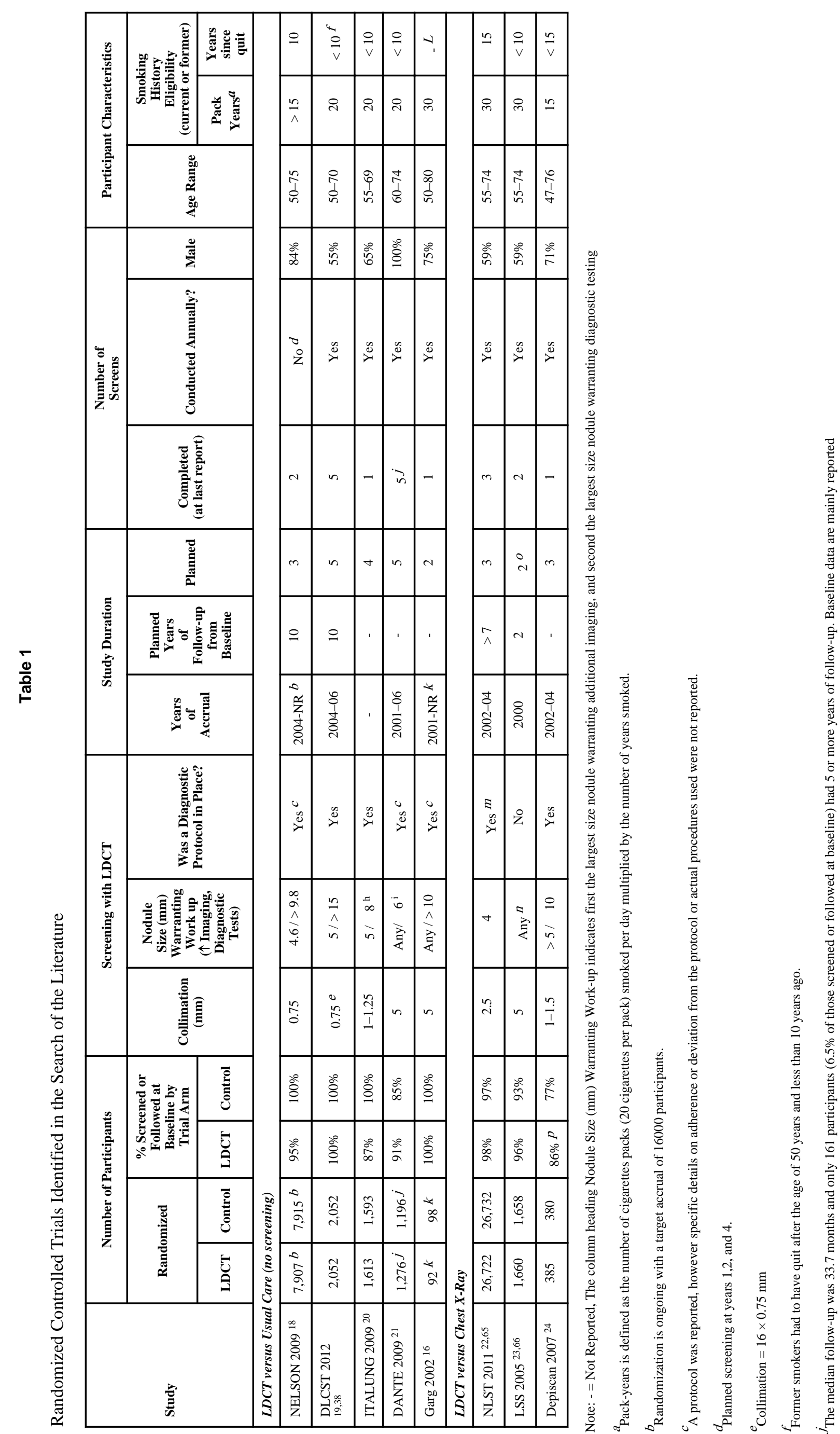




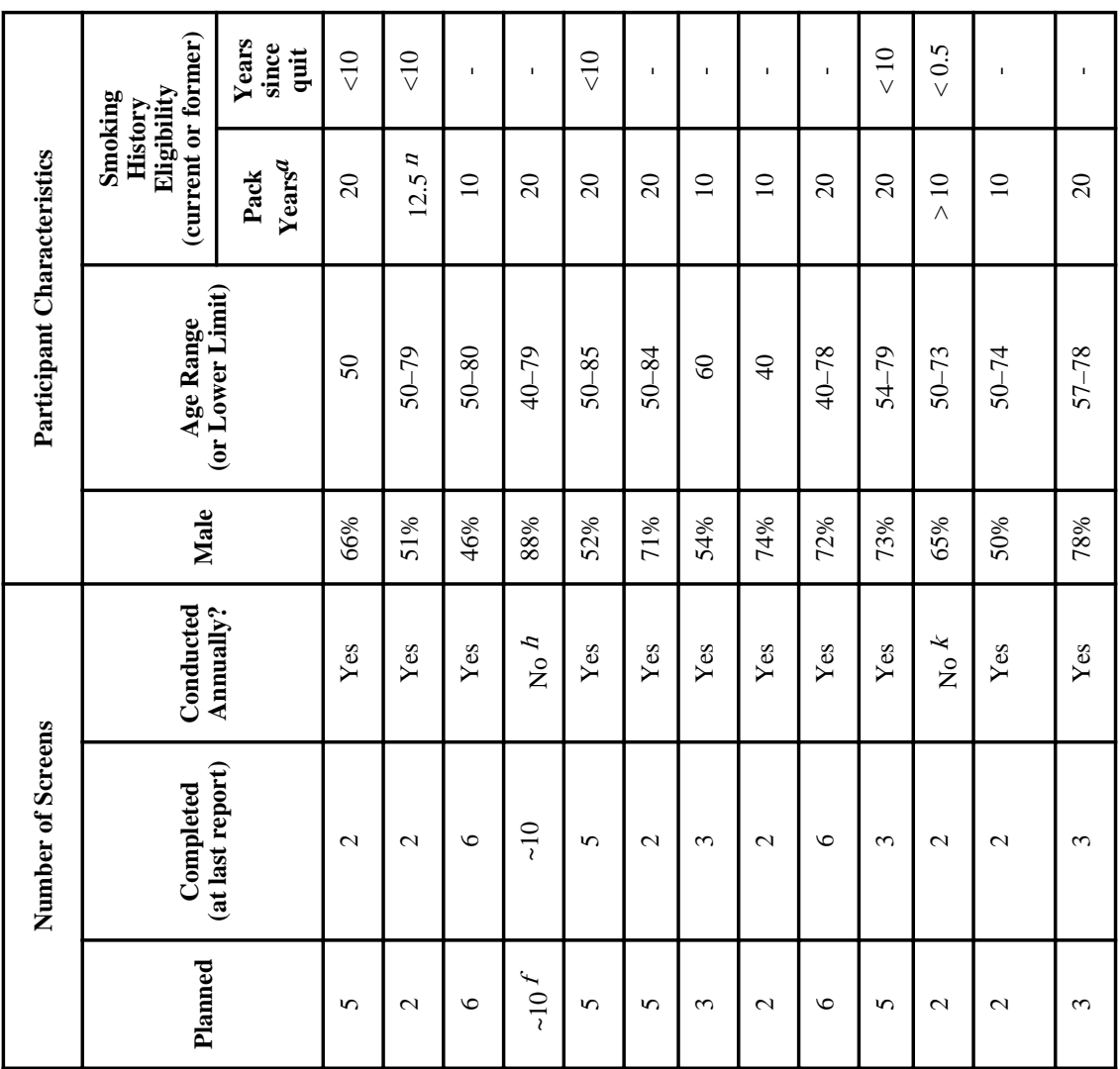

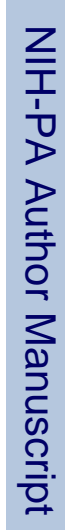

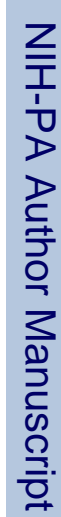

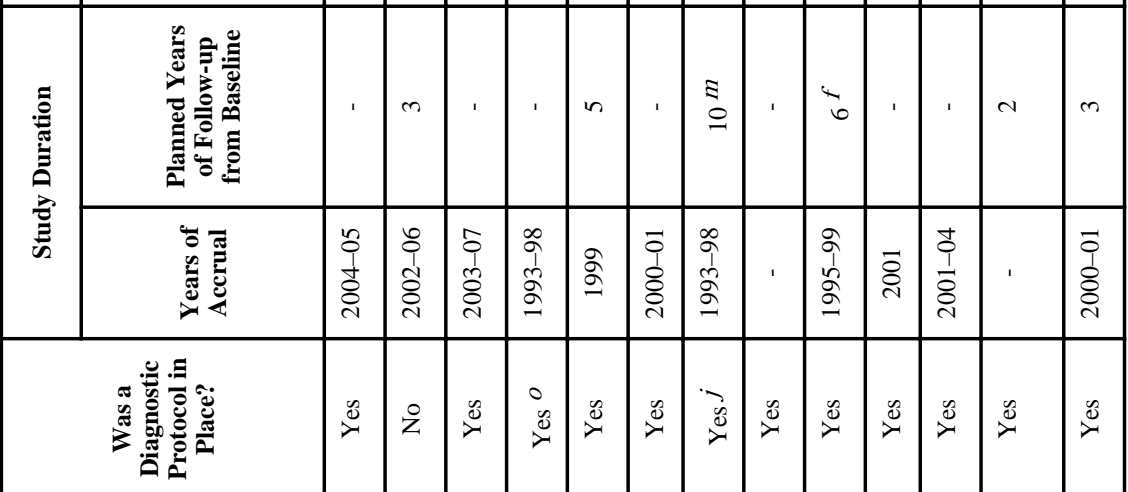

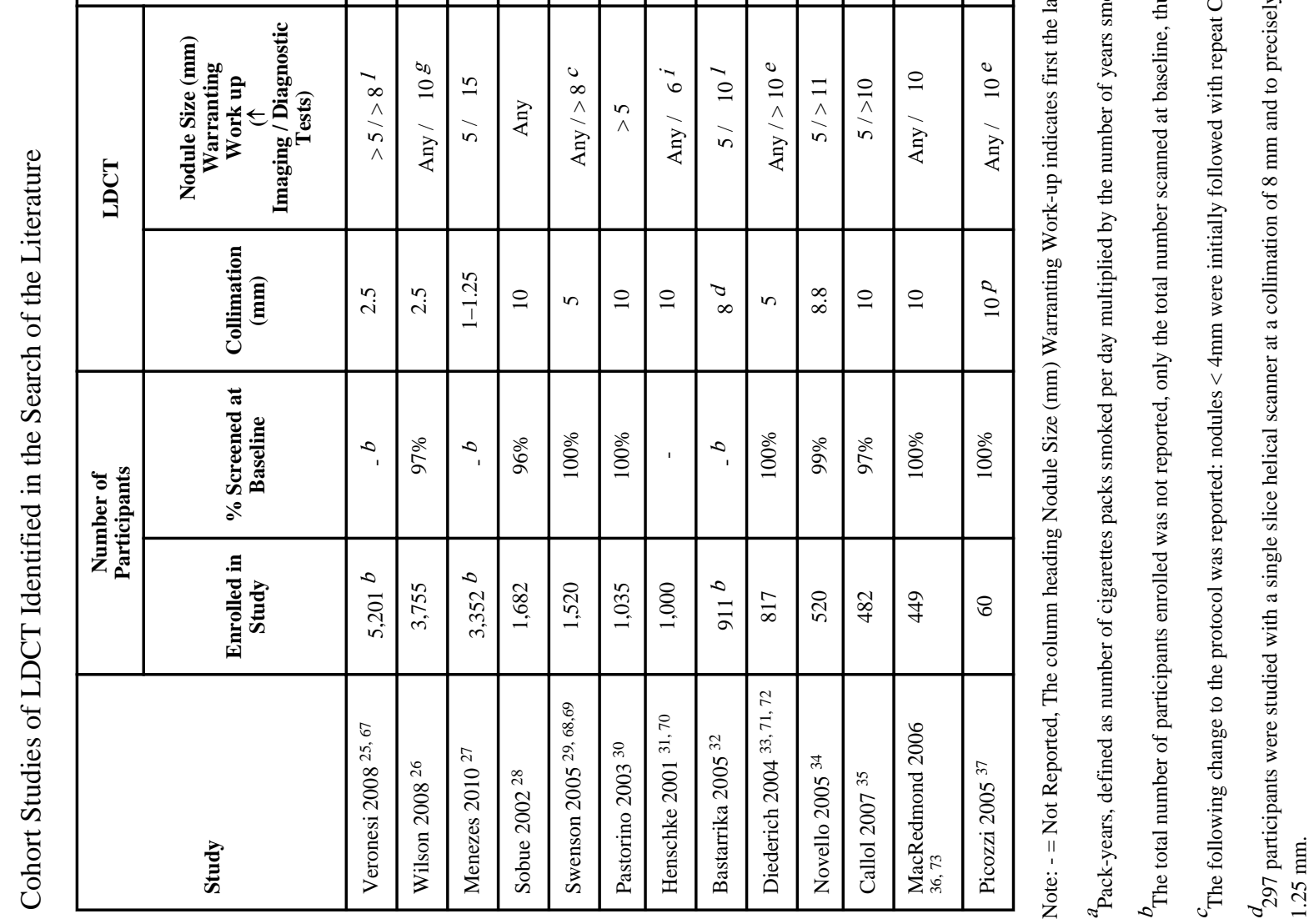

JAMA. Author manuscript; available in PMC 2013 July 12. 


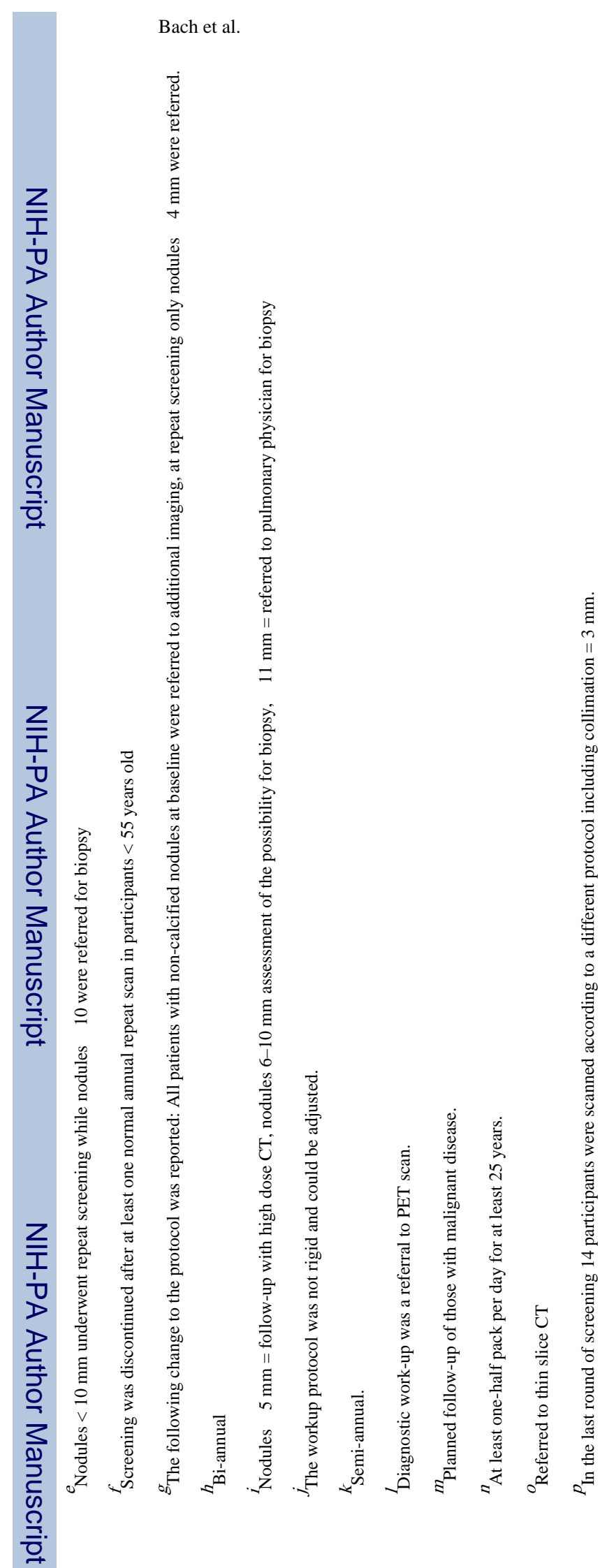

Page 18

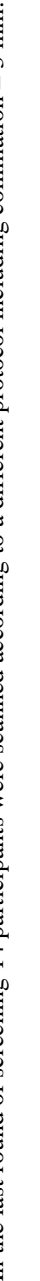




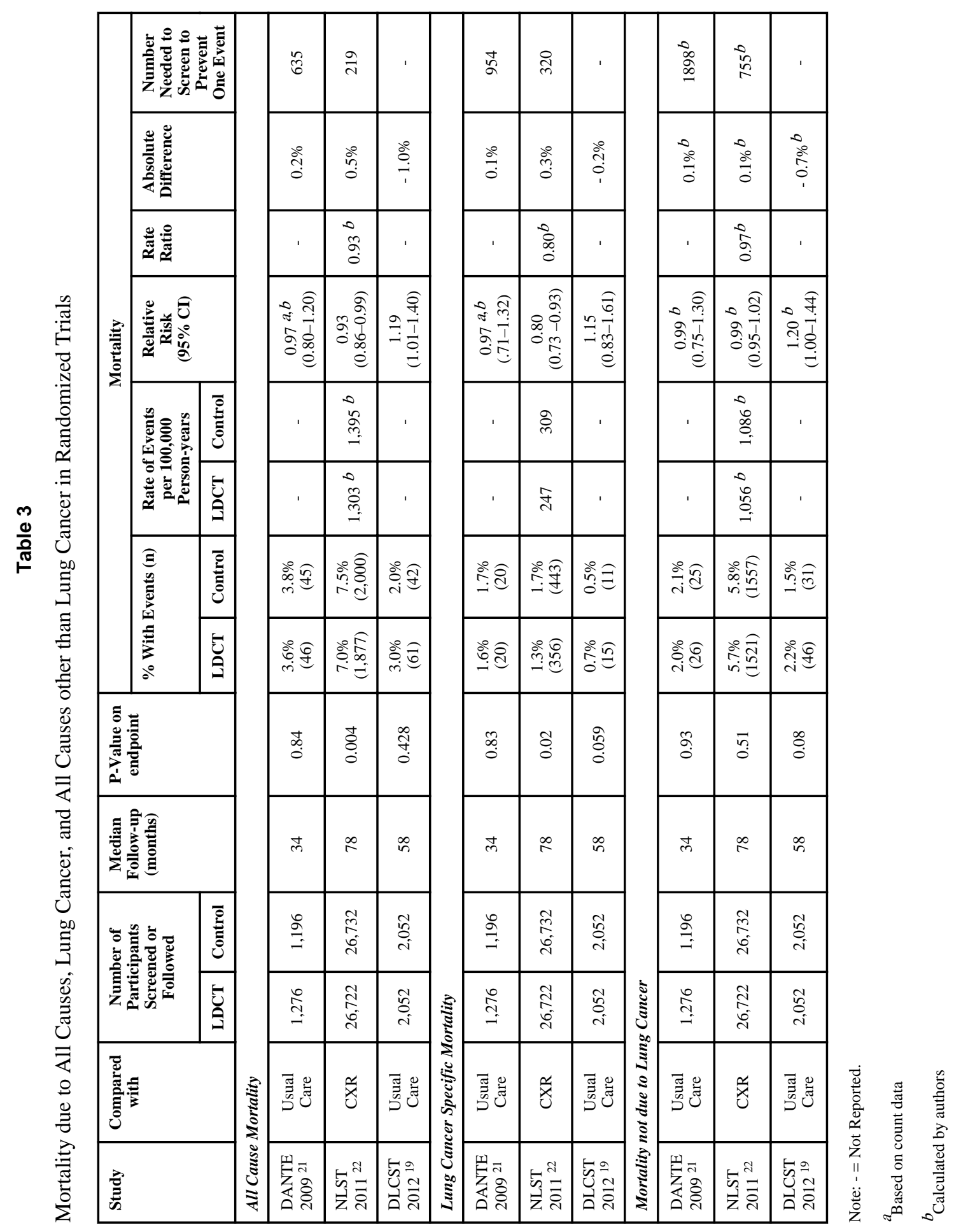

JAMA. Author manuscript; available in PMC 2013 July 12. 


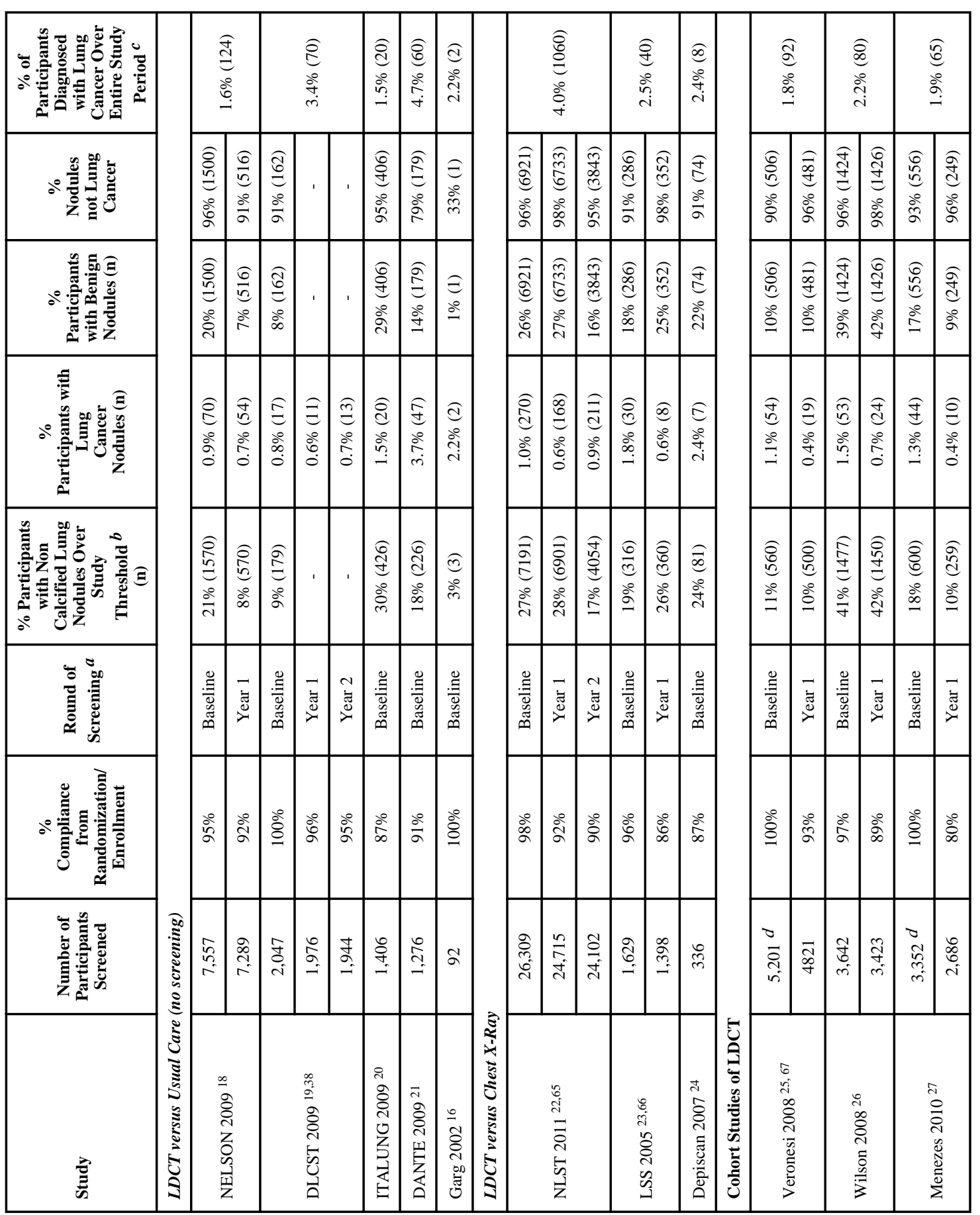




\begin{tabular}{|c|c|c|c|c|c|c|c|c|c|c|c|c|c|c|c|c|c|c|c|c|c|c|}
\hline 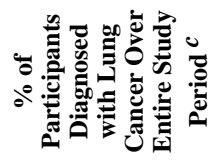 & & \multicolumn{3}{|c|}{$\begin{array}{l}\text { ठ̊ } \\
\stackrel{0}{0} \\
\stackrel{0}{1} \\
\text { i }\end{array}$} & \multicolumn{3}{|c|}{ 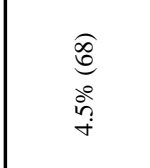 } & \multicolumn{2}{|c|}{$\begin{array}{l}\widehat{d} \\
\frac{d}{i} \\
\frac{0}{i}\end{array}$} & \multicolumn{2}{|c|}{ 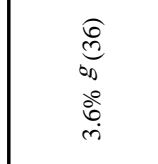 } & \multicolumn{2}{|c|}{ 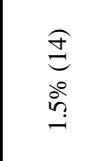 } & \multicolumn{2}{|r|}{ 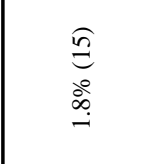 } & \multicolumn{3}{|c|}{ 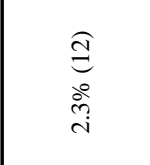 } & \multicolumn{2}{|c|}{$\begin{array}{l}\frac{6}{0} \\
\stackrel{0}{=}\end{array}$} & $\begin{array}{l}\stackrel{6}{0} \\
\stackrel{0}{\circ} \\
\stackrel{2}{\rightarrow}\end{array}$ & \multirow{2}{*}{ 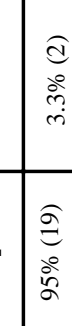 } \\
\hline 。ํ. & $\begin{array}{l}\frac{1}{d} \\
\therefore \\
\frac{0}{a}\end{array}$ & 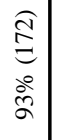 & $\begin{array}{l}\widehat{\circ} \\
\stackrel{0}{\circ} \\
\stackrel{0}{\circ}\end{array}$ & 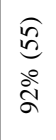 & 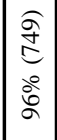 & 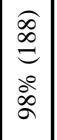 & , & 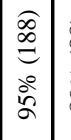 & $\begin{array}{l}\infty \\
\infty \\
\infty \\
\infty \\
\infty\end{array}$ & \begin{tabular}{|c|}
0 \\
0 \\
0 \\
$\circ$ \\
$\infty$ \\
$\infty$
\end{tabular} & 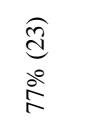 & $\begin{array}{l}\hat{\sigma} \\
\vdots \\
\frac{\sigma}{\sigma}\end{array}$ &, & 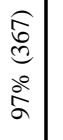 & & 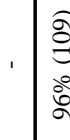 & 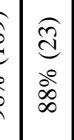 & $\begin{array}{c}\hat{\Omega} \\
\frac{0}{\infty} \\
\frac{0}{\infty}\end{array}$ & $\begin{array}{l}\widehat{c} \\
\hat{a} \\
\stackrel{0}{\circ} \\
\approx\end{array}$ & $\begin{array}{l}\approx \\
\therefore \\
8 \\
i\end{array}$ & & \\
\hline 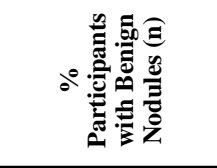 & $\begin{array}{l}\text { fo } \\
0 \\
0 \\
0\end{array}$ & $\begin{array}{l}\widehat{\hat{a}} \\
\triangleq \\
\stackrel{0}{=} \\
=\end{array}$ & 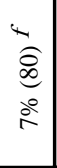 & $\begin{array}{l}n \\
6 \\
0 \\
0\end{array}$ & 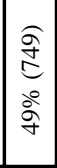 & 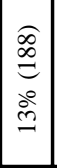 & , & $\begin{array}{l}\infty \\
\stackrel{\infty}{0} \\
\stackrel{0}{0} \\
\stackrel{\infty}{\infty}\end{array}$ & 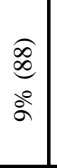 & \begin{tabular}{|c|}
0 \\
0 \\
0 \\
$\frac{2}{2}$ \\
$\frac{0}{2}$
\end{tabular} & & $\begin{array}{l}\stackrel{\varrho}{\Xi} \\
\stackrel{\circ}{\stackrel{0}{ٍ}}\end{array}$ & ' & 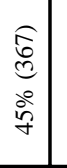 & & $\begin{array}{l}\frac{8}{2} \\
\frac{8}{2}\end{array}$ & 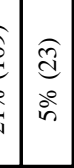 & $\mid \begin{array}{c}\hat{\Omega} \\
\stackrel{\infty}{0} \\
\stackrel{0}{0}\end{array}$ & 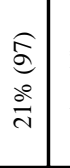 & $\begin{array}{l}6 \\
\stackrel{0}{0}\end{array}$ & & 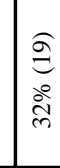 \\
\hline 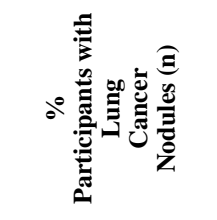 & $\begin{array}{l}0 \\
0 \\
0 \\
0 \\
0\end{array}$ & 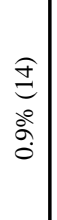 & $\begin{array}{l}\widehat{0} \\
\text { o } \\
\text { के } \\
0\end{array}$ & $\begin{array}{l}0 \\
0 \\
0 \\
0 \\
0\end{array}$ & $\begin{array}{l}\widehat{\vec{c}} \\
\stackrel{0}{2}\end{array}$ & 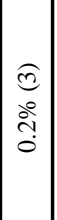 & ' & 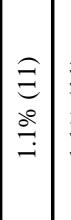 & $\begin{array}{l}\varrho \\
\Xi \\
\stackrel{0}{\Xi}\end{array}$ & \begin{tabular}{|c|}
$\hat{d}$ \\
$d$ \\
$\vdots$ \\
$\grave{i}$ \\
i
\end{tabular} & $\begin{array}{l}\stackrel{\infty}{E} \\
\vdots \\
0 \\
0 \\
0\end{array}$ & $\begin{array}{l}\widehat{\Omega} \\
\stackrel{\Omega}{0} \\
\stackrel{0}{=}\end{array}$ & $\begin{array}{l}2 \\
0 \\
0 \\
0 \\
0\end{array}$ & 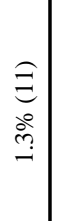 & & {$\left[\begin{array}{l}5 \\
0 \\
0\end{array}\right.$} & $\begin{array}{l}0 \\
0 \\
0 \\
0 \\
0\end{array}$ & $\begin{array}{l}\widehat{0} \\
0 \\
0 \\
0 \\
0\end{array}$ & 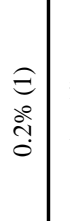 & $\begin{array}{l}Ð 0 \\
\stackrel{9}{-}\end{array}$ & \begin{tabular}{l|l}
$\widehat{c}$ & 0 \\
0 & 0 \\
0 & 0 \\
0 & 0 \\
0 & 0
\end{tabular} & $\begin{array}{l}\varrho \\
\vdots \\
\stackrel{0}{-}\end{array}$ \\
\hline 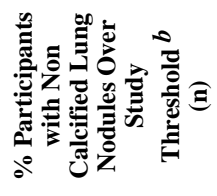 & $\begin{array}{l}\hat{尺} \\
\stackrel{0}{=}\end{array}$ & 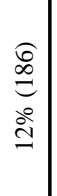 & ब্ळ & $\begin{array}{l}\widehat{\delta} \\
\stackrel{8}{\circ} \\
\therefore\end{array}$ & 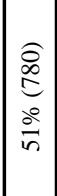 & $\begin{array}{l}\widehat{\sigma} \\
\partial \\
\stackrel{0}{0} \\
\stackrel{0}{2}\end{array}$ & ' & $\begin{array}{l}\widehat{a} \\
\stackrel{2}{2} \\
\stackrel{0}{\sigma}\end{array}$ & $\begin{array}{l}\hat{\sigma} \\
0 \\
0 \\
0\end{array}$ & 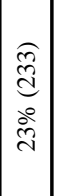 & $\begin{array}{l}\text { कo } \\
\stackrel{0}{0} \\
\text { ळ. }\end{array}$ & 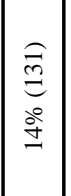 & ' & $\begin{array}{l}\infty \\
0 \\
0 \\
o \\
o \\
\dot{a}\end{array}$ & $\begin{array}{l}\hat{\tilde{\Xi}} \\
\vdots \\
\stackrel{0}{=}\end{array}$ & 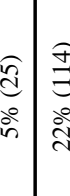 & $\begin{array}{l}0 \\
\text { d } \\
\text { i } \\
\text { in }\end{array}$ & $\begin{array}{l}6 \\
\stackrel{6}{7} \\
\stackrel{0}{i n}\end{array}$ & 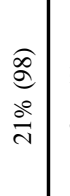 & $\begin{array}{l}\hat{a} \\
\text { dे }\end{array}$ & & $\begin{array}{l}\widehat{d} \\
\stackrel{d}{0} \\
\text { ले }\end{array}$ \\
\hline 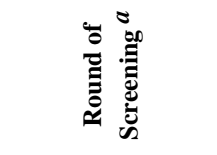 & 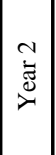 & 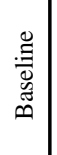 & $\begin{array}{l}0 \\
i \\
\vdots \\
\vdots \\
\bar{d} \\
2\end{array}$ & $\stackrel{0}{\bar{E}}$ & 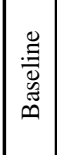 & $\overline{\vec{c}}$ & 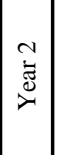 & 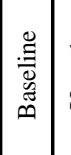 & $\overline{\vec{b}}$ & 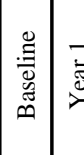 & 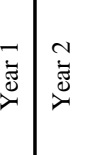 & 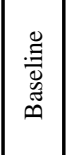 & 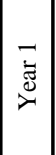 & 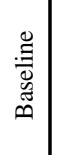 & ت气 & 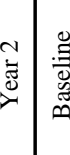 & $\overline{\vec{z}}$ & 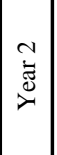 & 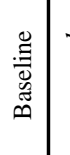 & 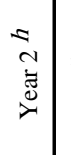 & 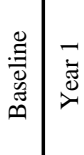 & 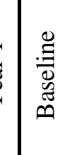 \\
\hline 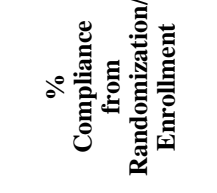 & 今̊ & $\stackrel{\circ}{\circ}$ & $\stackrel{\circ}{\stackrel{\circ}{\circ}}$ & in & $\stackrel{8}{\circ}$ & $\begin{array}{l}20 \\
\vdots \\
5\end{array}$ & 号 & $\stackrel{8}{\circ}$ & $\varliminf_{\circ}^{\circ}$ & 8 & 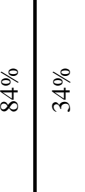 & $\stackrel{8}{\circ}$ & $\frac{8}{8}$ & 离 & ఏొ & \begin{tabular}{l|l}
8 \\
\\
\end{tabular} & $\frac{\alpha}{z}$ & 艺 & $\frac{8}{5}$ & $\frac{\stackrel{0}{0}^{\circ}}{+\infty}$ & ڤ̊ & $\stackrel{8}{0}$ \\
\hline 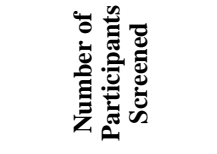 & : & $\vec{\Xi}$ & $\stackrel{\infty}{\stackrel{\infty}{=}}$ & $\bar{\infty}$ & 空 & 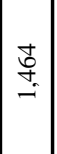 & 岂 & ్ֶ & ฉ & 8 & 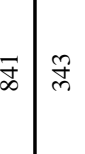 & $\bar{\sigma}$ & 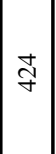 & $\frac{\Gamma}{\infty}$ & : & \begin{tabular}{l|l} 
oे \\
in
\end{tabular} & $\frac{\alpha}{z}$ & 妾 & 号 & ఫ্ & \begin{tabular}{l|l}
$q$ \\
$\forall$
\end{tabular} & 8 \\
\hline 总 & & & 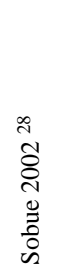 & & & $\begin{array}{l}8 \\
0 \\
0 \\
0 \\
o \\
0 \\
0 \\
0 \\
00 \\
0 \\
0\end{array}$ & & 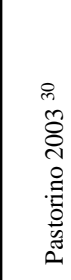 & $\begin{array}{l}6 \\
0 \\
0 \\
0 \\
0 \\
0 \\
0\end{array}$ & 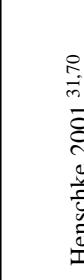 & 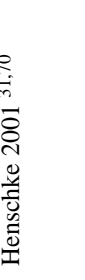 & 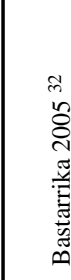 & & & 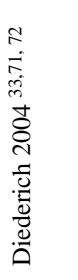 & & 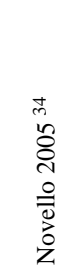 & & 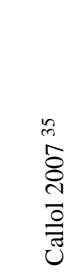 & & 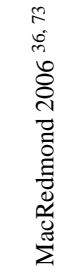 & 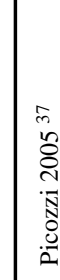 \\
\hline
\end{tabular}




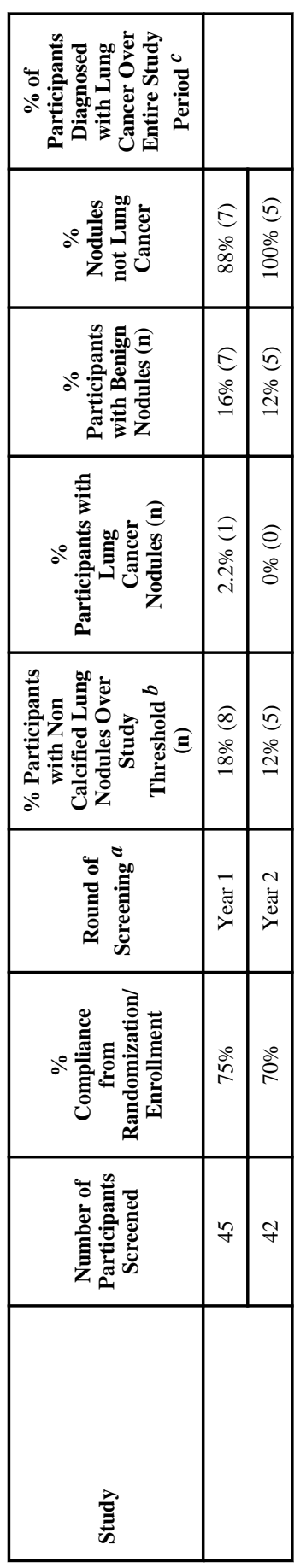

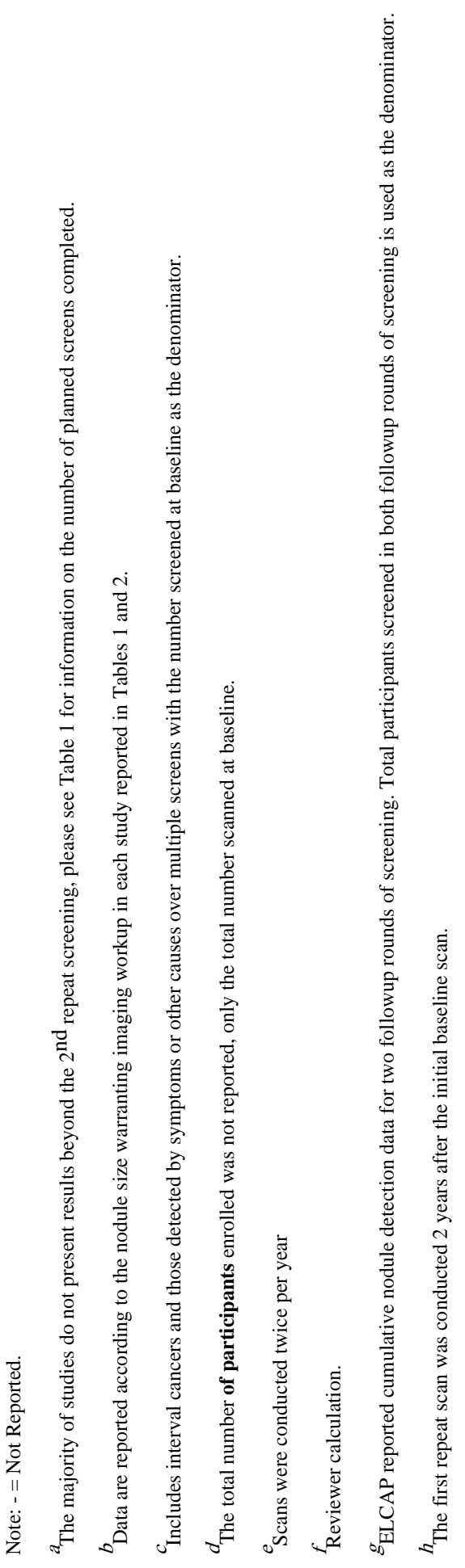

ํㅗㄹ 


\begin{tabular}{|c|c|c|c|c|c|c|c|c|c|c|c|c|c|c|c|c|c|c|c|c|c|c|}
\hline 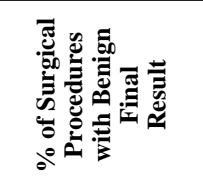 & & $\begin{array}{l}\frac{10}{8} \\
\stackrel{0}{0} \\
\stackrel{0}{0}\end{array}$ & $\begin{array}{l}0 \\
\infty \\
0 \\
0 \\
0 \\
0\end{array}$ & $\begin{array}{l}0 \\
0 \\
0\end{array}$ & 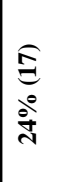 & & & 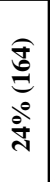 & 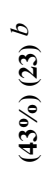 & 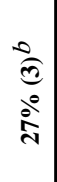 & & 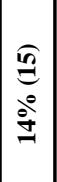 & 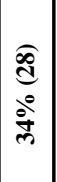 & & $\begin{array}{l}6 \\
0 \\
\stackrel{\operatorname{c}}{0}\end{array}$ & $\begin{array}{l}\infty \\
\dot{\infty} \\
\vec{\lambda}\end{array}$ & $\begin{array}{l}\frac{0}{6} \\
\frac{\sigma}{2} \\
\frac{0}{d}\end{array}$ & & $\begin{array}{l}\hat{\theta} \\
\stackrel{0}{\theta}\end{array}$ & $\begin{array}{c}\stackrel{0}{ \pm} \\
\frac{8}{0} \\
\frac{0}{d}\end{array}$ & & $\begin{array}{l}\text { वิ } \\
\therefore \\
\text { ते }\end{array}$ \\
\hline 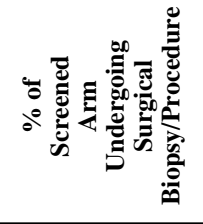 & & 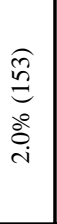 & 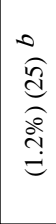 & $\begin{array}{c}\stackrel{6}{0} \\
\stackrel{0}{0} \\
=\end{array}$ & $\begin{array}{l}\widehat{\widehat{E}} \\
\mathrm{D} \\
\mathrm{o} \\
\text { in }\end{array}$ & & & $\begin{array}{l}\widehat{c} \\
\hat{\sigma} \\
0 \\
0 \\
i \\
\text { i }\end{array}$ & 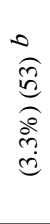 & $\begin{array}{l}\stackrel{0}{\Im} \\
\Xi \\
\stackrel{0}{m} \\
\dot{m}\end{array}$ & & $\begin{array}{l}0 \\
0 \\
0 \\
0 \\
0 \\
i\end{array}$ & $\begin{array}{l}\widehat{\sigma} \\
\infty \\
0 \\
\tilde{c} \\
\vec{i}\end{array}$ & & 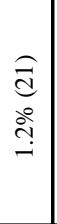 & 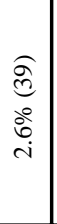 & $\begin{array}{l}\stackrel{0}{a d} \\
\stackrel{d}{d} \\
\stackrel{o}{0} \\
\stackrel{d}{d}\end{array}$ & & $\begin{array}{l}\hat{\widehat{O}} \\
\stackrel{0}{0} \\
\stackrel{g}{-}\end{array}$ & 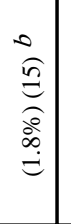 & & $\begin{array}{l}E \\
\stackrel{0}{\circ} \\
\stackrel{0}{n}\end{array}$ \\
\hline 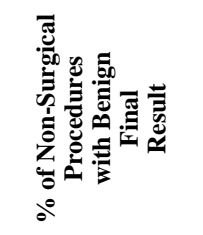 & & $\begin{array}{l}\widehat{\infty} \\
\stackrel{0}{0} \\
\stackrel{0}{0} \\
\stackrel{0}{n}\end{array}$ & 0 & $\begin{array}{l}Ð \\
\vdots \\
0\end{array}$ & & & & 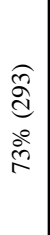 & $\because$ & & & $\begin{array}{l}\stackrel{\Omega}{\varrho} \\
\stackrel{0}{2} \\
\stackrel{0}{n}\end{array}$ & ' & $\begin{array}{l}\stackrel{6}{\varrho} \\
\frac{0}{2}\end{array}$ & $\begin{array}{l}\hat{\mathcal{d}} \\
\stackrel{0}{\infty} \\
i \\
i n\end{array}$ & & 0 & $\begin{array}{l}\text { a } \\
\text { do }\end{array}$ & 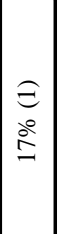 & $\therefore$ & & \\
\hline 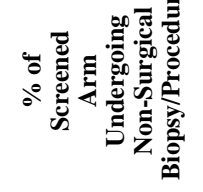 & & 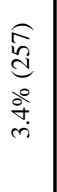 & 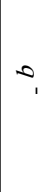 & $\begin{array}{l}\stackrel{6}{6} \\
\stackrel{0}{\circ} \\
\stackrel{0}{=}\end{array}$ & & & & 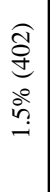 & $\because$ & 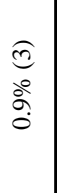 & & $\begin{array}{l}\widehat{\sigma} \\
\stackrel{\sigma}{0} \\
\stackrel{0}{-}\end{array}$ & . & 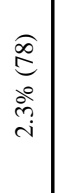 & 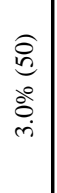 & & $\therefore$ & $\begin{array}{l}0 \\
\stackrel{e}{0} \\
\stackrel{0}{\circ} \\
\stackrel{\leftrightarrow}{\circ}\end{array}$ & $\begin{array}{l}0 \\
0 \\
\stackrel{0}{0} \\
0\end{array}$ & $\therefore$ & & \\
\hline 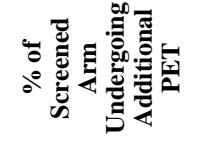 & & 0 & ' & 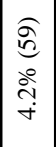 & $\begin{array}{l}\tilde{b} \\
\tilde{n} \\
\dot{v} \\
\dot{r}\end{array}$ & & & 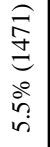 & & & & $\begin{array}{l}\underset{n}{n} \\
\stackrel{0}{0} \\
\dot{m}\end{array}$ & ' & & & & $\begin{array}{l}\frac{\widehat{d}}{d} \\
\frac{\Xi}{\vec{f}}\end{array}$ & & 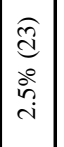 & ' & & \\
\hline 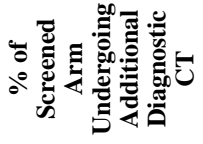 & & & , & & ' & $\begin{array}{l}\hat{\sigma} \\
\stackrel{0}{\infty} \\
\tilde{m}\end{array}$ & & $\begin{array}{l}E \\
\delta \\
\infty \\
\infty \\
\infty \\
\infty\end{array}$ & & & & $\begin{array}{l}\text { 舌 } \\
\text { 。o }\end{array}$ & ' & & 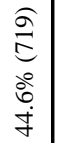 & & 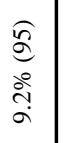 & & $\begin{array}{l}\widehat{o} \\
\text { o }\end{array}$ & ' & & , \\
\hline 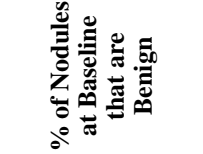 & & 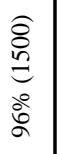 & $\begin{array}{l}\frac{1}{6} \\
\frac{0}{\sigma} \\
\frac{0}{a}\end{array}$ & 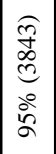 & 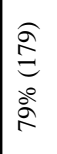 & $\begin{array}{l}\underset{\Xi}{\Xi} \\
\stackrel{\infty}{m}\end{array}$ & & 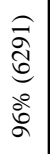 & 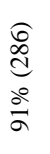 & $\begin{array}{l}\text { f } \\
\stackrel{5}{\circ} \\
\stackrel{5}{\sigma}\end{array}$ & & 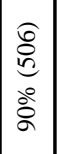 & 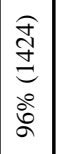 & 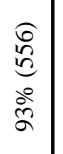 & 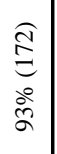 & 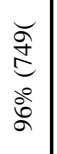 & 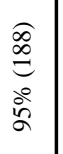 & $\begin{array}{l}0 \\
\stackrel{0}{ } \\
0 \\
\infty \\
\infty \\
\infty\end{array}$ & 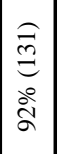 & 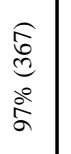 & 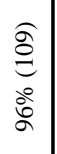 & \\
\hline 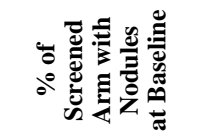 & & $\begin{array}{l}\underset{2}{2} \\
\stackrel{2}{2} \\
\frac{2}{2}\end{array}$ & $\begin{array}{l}\widehat{\widehat{\Xi}} \\
\stackrel{0}{\circ}\end{array}$ & 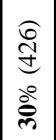 & 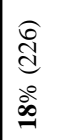 & $\begin{array}{l}\hat{0} \\
\text { ¿े }\end{array}$ & & 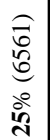 & $\begin{array}{l}\frac{6}{0} \\
\stackrel{0}{0} \\
\stackrel{0}{2}\end{array}$ & $\begin{array}{l}\widehat{\infty} \\
\stackrel{0}{0} \\
\stackrel{d}{d}\end{array}$ & & $\begin{array}{l}0 \\
0 \\
0 \\
0 \\
\stackrel{0}{0} \\
=\end{array}$ & 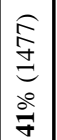 & $\begin{array}{l}\widehat{0} \\
\stackrel{0}{0} \\
\stackrel{0}{\circ}\end{array}$ & $\begin{array}{l}0 \\
\stackrel{0}{0} \\
\stackrel{0}{0} \\
\cong\end{array}$ & $\begin{array}{l}\widehat{O} \\
\stackrel{0}{0} \\
\stackrel{0}{\hat{n}}\end{array}$ & $\begin{array}{l}\widehat{\partial} \\
\stackrel{\partial}{\circ} \\
\stackrel{0}{\sigma}\end{array}$ & 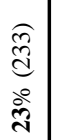 & 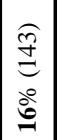 & 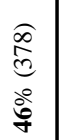 & 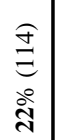 & \\
\hline 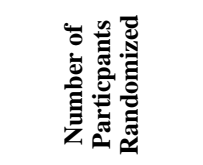 & & 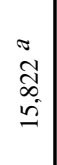 & 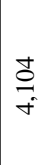 & $\begin{array}{l}\text { ते } \\
\text { लె }\end{array}$ & $\begin{array}{l}0 \\
\underset{\infty}{0} \\
i\end{array}$ & 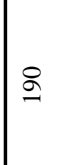 & 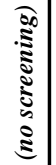 & $\begin{array}{l}\text { 孛 } \\
\text { in }\end{array}$ & $\frac{\infty}{m_{n}}$ & $\stackrel{8}{2}$ & & $\begin{array}{l}\vec{i} \\
\text { in }\end{array}$ & $\begin{array}{c}\tilde{n} \\
c \\
m\end{array}$ & $\begin{array}{l}\tilde{N} \\
\text { ले }\end{array}$ & 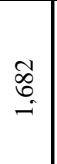 & 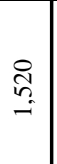 & $\stackrel{\infty}{0}_{-}^{\infty}$ & $\underset{-}{8}$ & $\bar{\sigma}$ & $\stackrel{\bar{\infty}}{-}$ & तิ & $\underset{\&}{\mathscr{\sigma}}$ \\
\hline 胥 & 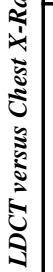 & 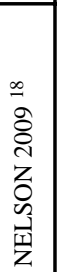 & 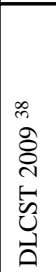 & 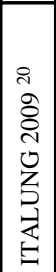 & 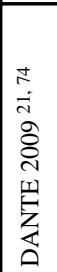 & 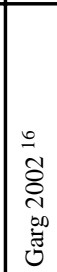 & 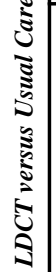 & 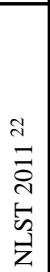 & 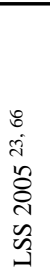 & 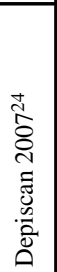 & 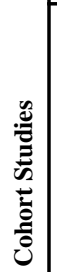 & 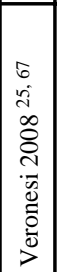 & 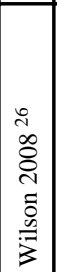 & 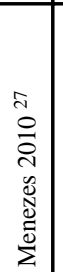 & 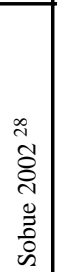 & $\begin{array}{l}8 \\
0 \\
0 \\
0 \\
0 \\
0 \\
0 \\
0 \\
0 \\
0 \\
0 \\
0 \\
0 \\
0\end{array}$ & 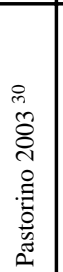 & 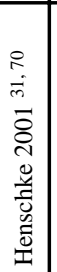 & 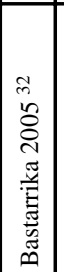 & 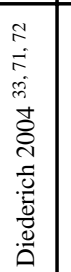 & 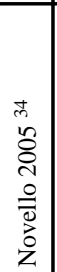 & 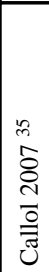 \\
\hline
\end{tabular}




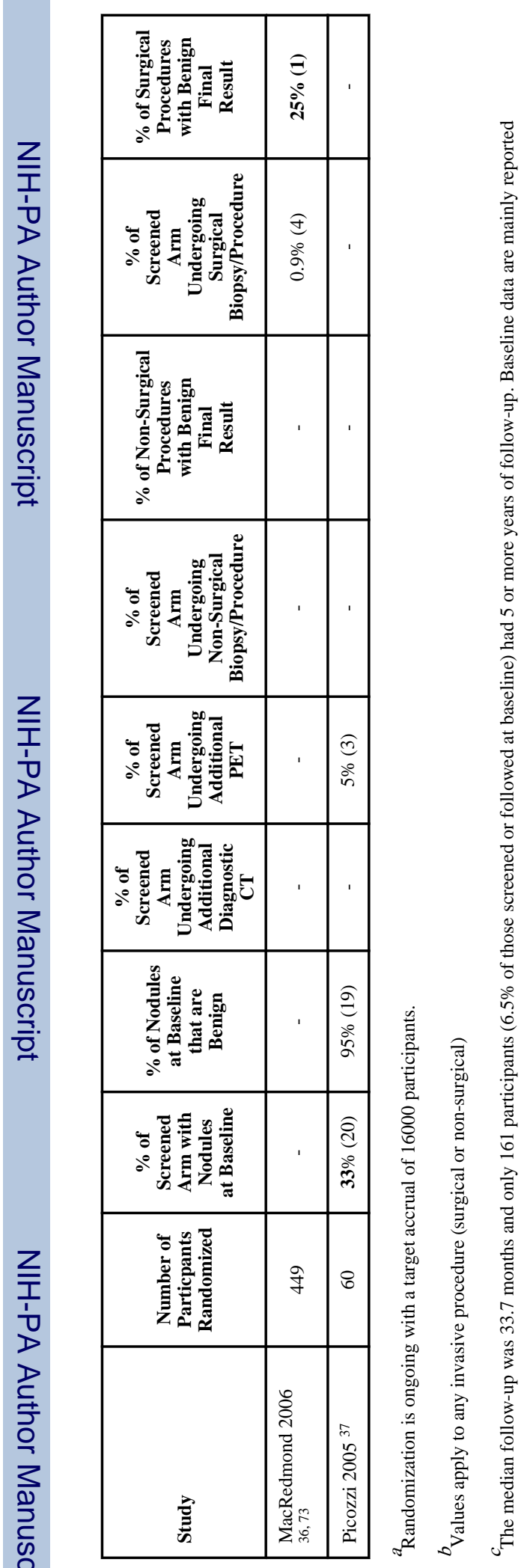


The role of CT screening for lung cancer: Recommendations from the American College of Chest Physicians and the American Society of Clinical Oncology ${ }^{1}$

\begin{tabular}{|c|c|}
\hline $\begin{array}{r}\text { Recommendation } \\
1\end{array}$ & $\begin{array}{l}\text { For smokers and former smokers who are age } 55 \text { to } 74 \text { and who have smoked for } 30 \text { pack years or } \\
\text { more and either continue to smoke or have quit within the past } 15 \text { years, we suggest that annual } \\
\text { screening with low-dose CT should be offered over both annual screening with chest radiograph or no } \\
\text { screening, but only in settings that can deliver the comprehensive care provided to NLST participants. } \\
\text { Grade of recommendation: 2B }\end{array}$ \\
\hline Remark 1 & $\begin{array}{l}\text { Counseling should include a complete description of potential benefits and harms, as outlined in } \\
\text { Tables } 1 \text { and 2, so the individual can decide whether or not to undergo LDCT screening. }\end{array}$ \\
\hline Remark 2 & $\begin{array}{l}\text { Screening should be conducted in a center similar to those where the National Lung Screening Trial } \\
\text { was conducted, with multi-disciplinary coordinated care and a comprehensive process for screening } \\
\text { image interpretation, management of findings, and evaluation and treatment of potential cancers. }\end{array}$ \\
\hline Remark 3 & $\begin{array}{l}\text { A number of important questions about screening could be addressed if individuals who are screened } \\
\text { for lung cancer are entered into a registry that captures data on follow-up testing, radiation exposure } \\
\text { patient experience, and smoking behavior. }\end{array}$ \\
\hline Remark 4 & $\begin{array}{l}\text { Quality metrics should be developed such as those in use for mammography screening, which could } \\
\text { help enhance the benefits and minimize the harm for individuals who undergo screening. }\end{array}$ \\
\hline Remark 5 & $\begin{array}{l}\text { Screening for lung cancer is not a substitute for stopping smoking. The most important thing patients } \\
\text { can do to prevent lung cancer is not smoke. }\end{array}$ \\
\hline Remark 6 & The most effective duration or frequency of screening is not known. \\
\hline $\begin{array}{r}\text { Recommendation } \\
2\end{array}$ & $\begin{array}{l}\text { For individuals who have accumulated fewer than } 30 \text { pack years of smoking or are either younger } \\
\text { than age } 55 \text { or older than } 74 \text {, or individuals who quit smoking more than } 15 \text { years ago, and for } \\
\text { individuals with severe comorbidities that would preclude potentially curative treatment and/or limit } \\
\text { life expectancy, we suggest that CT screening should not be performed. Grade of recommendation: } \\
\text { 2C. }\end{array}$ \\
\hline
\end{tabular}

${ }^{1}$ Full text of the ACCP and ASCO evidence based practice guideline on the role of $\mathrm{CT}$ screening for lung cancer is available in the online appendix. 